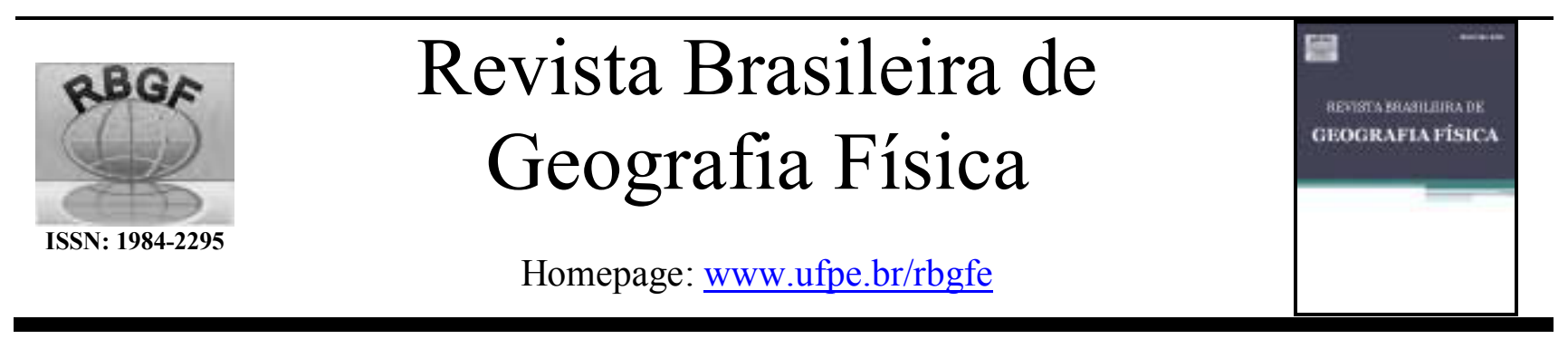

\title{
Impactos das mudanças climáticas na demanda hídrica e duração do ciclo do sorgo forrageiro e feijão-caupi no estado de Pernambuco
}

José Edson Florentino de Morais ${ }^{1}$; Thieres George Freire da Silva ${ }^{2}$; Marcela Lúcia Barbosa ${ }^{3}$; Wellington Jairo da Silva Diniz ${ }^{4}$; Carlos André Alves de Souza ${ }^{5}$; Alexandre Maniçoba da Rosa Ferraz Jardim ${ }^{6}$ Jadna Mylena da Silva Ferreira ${ }^{7}$

\begin{abstract}
${ }^{1}$ Mestrando em Produção Vegetal, Programa de Pós-graduação em Produção Vegetal, Universidade Federal Rural de Pernambuco/Unidade Acadêmica de Serra Talhada, Serra Talhada - PE, joseedson50@hotmail.com; ${ }^{2}$ Professor Adjunto III, Agrometeorologia, Universidade Federal Rural de Pernambuco/Unidade Acadêmica de Serra Talhada, Serra Talhada - PE, (autor correspondente), e-mail: thigeoprofissional@hotmail.com; ${ }^{3}$ Mestranda em Meteorologia Agrícola, Departamento de Eng. Agrícola, Universidade Federal de Viçosa, Viçosa - MG, marcelalucia.ufrpe@hotmail.com; ${ }^{4}$ Mestrando em Produção Vegetal, Programa de Pós-graduação em Produção Vegetal, Universidade Federal Rural de Pernambuco/Unidade Acadêmica de Serra Talhada, Serra Talhada - PE, wellingtonjairo@hotmail.com; ${ }^{5}$ Graduando em Eng. Agronômica, Universidade Federal Rural de Pernambuco/Unidade Acadêmica de Serra Talhada, Serra Talhada - PE, carlosandre08_@msn.com; ${ }^{6}$ Graduando em Eng. Agronômica, Universidade Federal Rural de Pernambuco/Unidade Acadêmica de Serra Talhada, Serra Talhada - PE, alexandremrfj@gmail.com; ${ }^{7}$ Graduanda em Eng. Agronômica, Universidade Federal Rural de Pernambuco/Unidade Acadêmica de Serra Talhada, Serra Talhada-PE, jadna.mylena@hotmail.com.
\end{abstract}

Artigo recebido em 10/09/2015 e aceito em 30/11/2015.

\section{RESUMO}

O aumento na ocorrência de eventos climáticos extremos nas últimas décadas é uma forte evidência das mudanças climáticas. Em regiões Semiáridas, onde a pressão de desertificação tem se intensificado, são esperadas diminuição da disponibilidade de água e maior ocorrência de períodos seca, e, consequentemente, efeitos na resposta fisiológica das plantas. Assim, objetivou-se analisar os impactos dos cenários de mudanças climáticas sobre a duração do ciclo fenológico e a demanda de água do sorgo forrageiro e do feijão-caupi cultivados no Estado de Pernambuco. Foram utilizados os valores mensais da normal climatológica brilho solar, temperatura do ar, umidade relativa do ar e velocidade do vento de dez municípios. Considerou-se um aumento de $1,8^{\circ} \mathrm{C}$ (Cenário $\mathrm{B} 2$ ) e $4,0^{\circ} \mathrm{C}$ (Cenário $\left.\mathrm{A} 1 \mathrm{~F} 1\right)$ na temperatura do ar e um decréscimo de $5,0 \%$ dos valores absolutos de umidade relativa do ar, além do aumento de $22 \%$ na resistência estomática e de 4\% no índice de área foliar. Com base nessas informações foram gerados três cenários: situação atual e projeções futuras para B2 e A1F1. Os resultados revelaram uma redução média de $11 \%$ (B2) e 20\% (A1F1), e de 10\% (B2) e 17\% (A1F1) na duração do ciclo, e de 4\% (B2) e 8\% (A1F1), e 2\% (B2) e 5\% (A1F1) na demanda de água acumulada para o sorgo forrageiro e feijão-caupi, respectivamente. Conclui-se que a magnitude das reduções da duração do ciclo e a demanda de água simulada para as culturas do sorgo forrageiro e do feijão-caupi variaram espaço-temporalmente no Estado de Pernambuco com os cenários de mudanças climáticas.

Palavras-chave: aquecimento global, dióxido de carbono, evapotranspiração, Sorghum bicolor (L.) Moench, Vigna unguiculata (L.) Walp.

\section{Impacts of climate change on water demand and duration forage sorghum and cowpea cycle in the state of Pernambuco}

\begin{abstract}
The increase in the occurrence of extreme weather events in recent decades is a strong evidence of climate change. In semiarid regions, where the pressure of desertification has intensified, are expected to decrease in the availability of water and higher occurrence of drought periods, and, consequently, effects on physiological response of plants. Thus, the objective of analyzing the impacts of climate change scenarios on the duration of phenological cycle and water demand of forage sorghum and cowpea, grown in the State of Pernambuco. Monthly values were used normal climatological solar brightness, air temperature, relative humidity and wind speed of ten municipalities. It was considered an increase of $1.8^{\circ} \mathrm{C}\left(\mathrm{B} 2\right.$ Scenario) and $4.0^{\circ} \mathrm{C}(\mathrm{A} 1 \mathrm{~F} 1 \mathrm{Scenario})$ on air temperature and a decrease of $5.0 \%$ of the absolute values of relative humidity, in addition to the $22 \%$ increase in stomatal resistance and $4 \%$ in leaf area index. Based on this information were generated three scenarios: current situation and future projections for B2, A1F1.
\end{abstract}

Morais, J. E. F.; Silva; T. G. F.; Barbosa; M. L.; Diniz, W. J. S.; Souza, C. A. A.; Jardim, A. M. R. F.; Ferreira, J. M. S. 
The results revealed an average reduction of $11 \%(\mathrm{~B} 2)$ and $20 \%(\mathrm{~A} 1 \mathrm{~F} 1)$, and $10 \%$ (B2) and $17 \%$ (A1F1) for the duration of the cycle, and 4\% (B2) and $8 \%(\mathrm{~A} 1 \mathrm{~F} 1)$, and $2 \%(\mathrm{~B} 2)$ and $5 \%(\mathrm{~A} 1 \mathrm{~F} 1)$ in accumulated water demand for forage sorghum and cowpea, respectively. It is concluded that the magnitude of the reductions in the duration of the cycle and the simulated water demand for crops of forage sorghum and cowpea ranged space-temporarily in the State of Pernambuco with climate change scenarios.

Keywords: global heating, carbon dioxide, evapotranspiration, Sorghum bicolor (L.) Moench; Vigna unguiculata (L.) Walp.

\section{Introdução}

As mudanças climáticas globais são decorrentes, sobretudo, do acúmulo de gases de efeito estufa (GEF) na atmosfera, dentre os quais se destacam o dióxido de carbono $\left(\mathrm{CO}_{2}\right)$, metano $\left(\mathrm{CH}_{4}\right)$ e óxidos nitrosos $\left(\mathrm{NO}_{\mathrm{x}}\right)$, associados ainda ao vapor d'água (Solomon et al., 2007; Grandis et al., 2010).

De acordo com as projeções do quarto relatório de Avaliação das Mudanças do Clima do Planeta organizado pelo Intergovernmental Panel on Climate Change (IPCC-AR4), a relação de mistura de $\mathrm{CO}_{2}$ na atmosfera aumentou globalmente cerca de $100 \mathrm{ppm}(+36 \%)$ ao longo dos últimos 250 anos, passando de $280 \mathrm{ppm}$ na era pré-industrial, para 379 ppm em 2005. Prevê-se ainda, que está concentração poderá atingir entre 730 e 1020 ppm no final do século XXI. Isso acarretará uma elevação da temperatura global de até $+1,8{ }^{\circ} \mathrm{C}$ (faixa provável de $1,1^{\circ} \mathrm{C}$ a $2,9^{\circ} \mathrm{C}$ ), de acordo com as estimativas para o cenário mais otimista (B1) (IPCC, 2007).

O quinto relatório (IPCC-AR5), publicado em 2013, reforçou as evidências sobre as mudanças climáticas publicadas anteriormente (IPCC-AR4), fundamentadas em análises científicas independentes, observações e estudos teóricos dos processos climáticos e de simulações que utilizam modelagem. O AR5 apontou ainda o aumento da temperatura média da Terra como evidente e que, mudanças observadas (aquecimento da atmosfera e dos oceanos, diminuição das superfícies de gelo e neve, elevação do nível do mar e aumento nas concentrações de gases de efeito estufa) se intensificaram com a queima de combustíveis fósseis após a Revolução Industrial no século XVIII-XIX (IPCC, 2013).

De acordo com Valverde e Marengo (2014) há fortes evidências de que essas mudanças no clima podem afetar expressivamente o planeta, com maior rigor nos países menos desenvolvidos situados na região tropical, especialmente, em relação aos extremos climáticos. Nesse contexto, Reboita et al. (2014) destacam que o Brasil pode tornar-se vulnerável às mudanças climáticas atuais $\mathrm{e}$, mais ainda, às que se projetam para o futuro, sobretudo, aquelas associadas aos extremos climáticos como: El Niño e La Niña, secas, inundações, geadas e granizo.

Estudos realizados por Oyama e Nobre (2003) colocam a região Semiárida do Brasil em estado especial de alerta, uma vez que a vulnerabilidade do bioma Caatinga representa um forte fator de pressão para a desertificação. Essa região compreende $969.589,4 \mathrm{~km}^{2}$ ou $11 \%$ do território nacional, sendo caracterizada pelas elevadas médias anuais de temperatura $\left(27^{\circ} \mathrm{C}\right) \mathrm{e}$ evaporação $(2.000 \mathrm{~mm})$, com precipitações pluviométricas de até $800 \mathrm{~mm}^{2} \mathrm{ano}^{-1}$, concentradas em três a cincos meses e irregularmente distribuídas no tempo e no espaço, gerando um balanço hídrico negativo em grande parte do ano (Lima et al., 2011). Associadas as características naturais, as atividades antrópicas de remoção da vegetação de Caatinga para a exploração agropecuária e industrial aumentam a pressão da desertificação no Semiárido do Nordeste. Trabalhos realizados por Lacerda (2010), citados por Nobre (2011), para o município de Araripina, Sertão de Pernambuco, revelam aumento de $4{ }^{\circ} \mathrm{C}$ na temperatura máxima diária no período de 1961 a 2009 e diminuição média de $275 \mathrm{~mm}$ (-57\%) dos totais pluviométricos anuais, cujos impactos sobre as culturas agrícolas ainda não são totalmente conhecidos.

Segundo Godoy (2007) e Rocha et al. (2012), são três os processos principais que fazem com que a as plantas respondam ao aumento da concentração atmosférica de $\mathrm{CO}_{2}$ na atmosfera: 1 - sensibilidade das células-guarda dos estômatos; 2 - modulação da atividade da Rubisco; 3 modulação da respiração mitocondrial. Isso ocorre devido à capacidade desse gás aumentar a atividade fotossintética e diminuir a fotorrespiração pela diminuição da atividade de oxigenase da Rubisco. Outros efeitos esperados são a redução da condutância estomática, o aumento da eficiência de uso da água e da proporção $\mathrm{C} / \mathrm{N}$ (carbono/nitrogênio), que trazem como consequência uma diminuição na transpiração, aumento na taxa de crescimento e redução na duração do ciclo das plantas (Bernacchi et al., 2007; Marabesi, 2007; Souza et al., 2008; Grandis et al., 2010). Ainsworth e Long 
(2005), realizando estudos em ambiente controlado, evidenciaram que plantas crescidas sob altas concentrações de $\mathrm{CO}_{2}$ e saturação de luz mostram aumento de $31 \%$ na taxa de assimilação, diminuição na condutância estomática de aproximadamente $22 \%$ e um aumento de $50 \%$ na eficiência do uso de água.

As plantas $\mathrm{C} 4$, como o sorgo forrageiro, apresentam uma estrutura denominada de "anatomia Kranz", que se caracteriza por um feixe vascular bastante desenvolvido, rodeado por células o que confere menor espaço intercelular. A alta concentração de $\mathrm{CO}_{2}$ e baixa de $\mathrm{O}_{2}$ no sítio de atividade da Rubisco devido à anatomia Kranz limitam a fotorrespiração. Como evoluíram primariamente nos trópicos, são espécies adaptadas a altas intensidades luminosas, altas temperaturas e seca (Beltrão, 2008; Taiz e Zeiger, 2009; Raven et al., 2014). Por sua vez, as plantas C3, como feijão-caupi, apresentam maior taxa de fotorrespiração, processo de desperdício, não produzindo nem ATP nem NADH e são mais sensíveis ao aumento da temperatura do ar, saturando em intensidades luminosas mais baixas (Taiz e Zeiger, 2009).

De acordo com Rodrigues Filho et al. (2006), o sorgo forrageiro é uma cultura que apresenta alta produtividade e adaptação a ambientes secos e quentes, necessitando de temperaturas superiores a $20^{\circ} \mathrm{C}$ para seu desenvolvimento, o que permite o seu cultivo em regiões com distribuição irregular de chuvas e sucessão a culturas de verão garantindo estabilidade na atividade pecuária. Devido a sua característica de maior tolerância ao déficit hídrico, tem sua potencialidade para o cultivo na região Nordeste, onde atualmente é cultivado principalmente por pequenos produtores em sistema consorciado. Nesta região, Pernambuco ocupa a segunda posição com uma produção média de 10,7 toneladas por hectare para a produção de 2012/2013 de acordo com dados da Companhia Nacional de Abastecimento (CONAB, 2013). Ainda em Pernambuco, a área registrada de cultivo de sorgo foi 21.164 hectares, para o ano agrícola de 2008 (Tabosa et al., 2007). Assim, o zoneamento de risco climático (BRASIL, 2009) indica para Pernambuco uma área potencial de sorgo da ordem de um milhão de hectares, sendo destes, $300 \mathrm{mil}$ hectares de aptidão plena, sem nenhum impedimento de ordem climática e edáfica.

Por sua vez, a cultura do feijão-caupi, é mundialmente cultivada com expressão na Nigéria, Niger e Brasil (Rocha et al., 2009). No período de 2005 a 2009 o Brasil tornou-se um destaque no cenário mundial como terceiro maior produtor, com uma área cultivada de 1.391 .386 ha, e produção de 513.619 t (AGRIANUAL, 2010). Sendo a maior contribuição vinda da região Nordeste com uma área 1,2 milhão de hectares, onde se concentram as maiores produções (FAO, 2007). Desse modo, a cultura apresenta grande importância socioeconômica, sobretudo para a população rural, representando um dos principais componentes na dieta alimentar, além de ser responsável por fixar mão-de-obra no campo, gerar emprego e renda (Freire Filho, 2011; Silva et al., 2013). Em Pernambuco, o feijão-caupi é cultivado principalmente em sistema de sequeiro e consorciado com outras culturas como milho, mamona e mandioca (Furtado et al., 2014).

Neste contexto, há uma necessidade iminente em se estudar os efeitos das mudanças climáticas, para produção vegetal, já que culturas tolerantes a altas temperaturas e mais eficientes no uso do $\mathrm{CO}_{2}$ provavelmente serão beneficiadas até o seu limite próprio de tolerância. Assim, o objetivo deste trabalho foi analisar os impactos dos cenários de mudanças climáticas sobre a duração do ciclo fenológico e a demanda de água do sorgo forrageiro e do feijão-caupi cultivados no Estado de Pernambuco.

\section{Material e Métodos}

Descrição da área de estudo

O estudo foi realizado em dez municípios do Estado de Pernambuco (Tabela 1), distribuídos em quatro Mesorregiões climaticamente distintas: Recife (Mesorregião Metropolitana), com clima Am (tropical monçônico); Surubim, Caruaru, Garanhuns e Pesqueira (Mesorregião do Agreste), com clima As (tropical com estação seca de Verão); Arcoverde, Triunfo (Meso-região do Sertão), com clima BSh (semiárido quente), Floresta, Cabrobó e Petrolina (Mesorregião do São Francisco) com clima BSwh (semiárido quente), segundo a classificação de Köppen (1936) citado por Alvares et al. (2014).

\section{Dados climáticos utilizados}

Foram utilizadas as normais climatológicas da brilho solar (horas); temperatura média do ar $\left(\mathrm{t}^{\circ} \mathrm{C}\right)$; umidade relativa do ar (\%UR) e velocidade

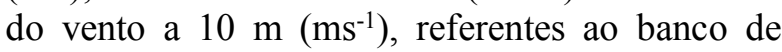
dados normais climatológicas do Brasil do período de 1960 a 1991, das estações meteorológicas convencionais pertencentes ao Instituto Nacional de Meteorologia (INMET), conforme demostrado na Tabela 2. 
Duração do ciclo e demanda de água

Para todas as localidades, analisaram-se os efeitos do aumento da concentração do dióxido de carbono $\left(\mathrm{CO}_{2}\right)$ e do déficit de pressão de vapor d'água sobre a duração do ciclo e a demanda de água do sorgo forrageiro e do feijão-caupi.

A duração do ciclo da cultura (DCC) foi determinada em função dos graus dias acumulados (GDA), considerando a exigência térmica, ou graus dias acumulados (GDA) de $1574{ }^{\circ} \mathrm{C}$ dia e a temperatura base (tb) de $10{ }^{\circ} \mathrm{C}$ para o sorgo forrageiro (Assis e Verona, 1991). Para o feijão-caupi foram adotados os valores de $1261,7^{\circ} \mathrm{C}$ dia e de $10{ }^{\circ} \mathrm{C}$ pra o feijão-caupi, nessa mesma ordem (Miranda e Campelo Júnior, 2010). A DCC foi calculada pela expressão:

$$
\mathrm{DCC}=\frac{\mathrm{GDA}}{\left(\mathrm{t}_{\text {méd. }}-\mathrm{tb}\right)}
$$

A demanda de água da cultura foi calculada pelo produto da evapotranspiração de referência, calculada pelo método original de Penman $(\lambda E T)$, com o coeficiente de cultura médio $(\mathrm{Kc})$, que conforme sugerido por Allen et al. (1998) é igual a 0,67 e 0,7 , respectivamente.

$\lambda E T$ foi obtida pela equação:

$$
\lambda \mathrm{ET}=\frac{\Delta(\mathrm{Rn}-\mathrm{G})+\rho_{a} c_{p} \mathrm{u}_{2}\left(\frac{\mathrm{e}_{\mathrm{s}}-\mathrm{e}_{\mathrm{a}}}{\mathrm{r}_{\mathrm{a}}}\right)}{\Delta+\gamma\left(1+\frac{\mathrm{r}_{\mathrm{s}}}{\mathrm{r}_{\mathrm{a}}}\right)}
$$

onde, $\Delta=$ declividade da curva da relação entre a pressão de saturação do vapor e a temperatura média do ar $\left(\mathrm{kPa}^{\circ} \mathrm{C}^{-1}\right) ; \mathrm{Rn}=$ radiação líquida $(\mathrm{MJ}$ $\left.\mathrm{m}^{-2} \mathrm{dia}^{-1}\right) ; \mathrm{G}=$ fluxo de calor no solo (MJ m${ }^{-2} \mathrm{dia}^{-}$ $\left.{ }^{1}\right) ; \rho_{\mathrm{a}}=$ densidade média do ar à pressão constante $\left(\mathrm{Kg} \mathrm{m}^{-3}\right) ; \mathrm{c}_{\mathrm{p}}=$ calor específico do ar $\left(\mathrm{MJ} \mathrm{Kg}^{-1}{ }^{\circ} \mathrm{C}^{-}\right.$ $\left.{ }^{1}\right) ; \quad\left(\mathrm{e}_{\mathrm{s}}-\mathrm{e}_{\mathrm{a}}\right) \quad$ déficit de pressão do vapor do ar $(\mathrm{kPa}) ; \gamma=$ constante psicrométrica $\left(\mathrm{kPa} \quad{ }^{\circ} \mathrm{C}^{-1}\right) ; \mathrm{r}_{\mathrm{s}}=$ resistência da superfície $\left(\mathrm{m} \mathrm{s}^{-1}\right) ; \mathrm{r}_{\mathrm{a}}=$ resistência aerodinâmica $(\mathrm{m}$ $\left.\mathrm{s}^{-1}\right)$.

Os dados do $\mathrm{Rn}$ foram estimados pelas equações (Allen et al., 1998):

$$
\mathrm{Rn}=\mathrm{Rns}-\mathrm{Rnl}
$$

Rns $=(1-\alpha) \operatorname{Rs}$

$\mathrm{Rnl}=\left[\begin{array}{l}\sigma\left(\mathrm{t}_{\text {méd }}+273,16\right)^{4} \cdot\left(0,34-0,14 \sqrt{\mathrm{e}_{\mathrm{a}}}\right) \\ \left(0,1+0,9 \cdot \frac{\mathrm{n}}{\mathrm{N}}\right)\end{array}\right]$

$$
\operatorname{Rs}=\left(\mathrm{a}+\mathrm{b} \cdot \frac{\mathrm{n}}{\mathrm{N}}\right) \cdot \mathrm{R}_{\mathrm{a}}
$$

$$
\begin{aligned}
& \mathrm{R}_{\mathrm{a}}=37,6 \mathrm{~d}_{\mathrm{r}}(\omega \operatorname{sen} \phi \cdot \operatorname{sen} \delta \\
& \left.+\cos \phi \cdot \cos \delta \cdot \operatorname{sen} \omega_{s}\right)
\end{aligned}
$$

$$
\mathrm{d}_{\mathrm{r}}=1+0,033 \cos \left(\frac{2 \pi}{365} \mathrm{~J}\right)
$$

$$
\begin{aligned}
& \delta=0,409 \cdot \operatorname{sen}\left(\frac{2 \pi}{365} \mathrm{~J}-1,39\right) \\
& \omega_{\mathrm{s}}=\operatorname{arcos}(-\tan \varphi \cdot \tan \delta)
\end{aligned}
$$

$\mathrm{N}=\frac{2 \omega_{\mathrm{S}}}{15}$

em que, Rns = radiação líquida de ondas curtas (MJ m $\left.{ }^{-2} \mathrm{~d}^{-1}\right) ; \mathrm{Rnl}=$ radiação líquida de ondas longas $\left(\mathrm{MJ} \mathrm{m}^{-2} \mathrm{~d}^{-1}\right) ; \mathrm{Rn}=$ saldo de radiação $(\mathrm{MJ}$ $\left.\mathrm{m}^{-2} \mathrm{~d}^{-1}\right) ; \quad \sigma=$ constante de Stefan-Boltzmann $\left(4,903 \times 10^{-9} \mathrm{MJ} \mathrm{m}^{-2} \mathrm{~d}^{-1}\right) ; \mathrm{t}_{\text {méd }}=$ temperatura média do $\operatorname{ar}\left({ }^{\circ} \mathrm{C}\right) ; \mathrm{n} / \mathrm{N}=$ relação entre o brilho solar e o fotoperíodo (adimensional); $\mathrm{Ra}=$ radiação solar extraterrestre $\left(\mathrm{MJ} \mathrm{m} \mathrm{m}^{-2} \mathrm{~d}^{-1}\right) ; \mathrm{d}_{\mathrm{r}}=$ inverso do quadrado da distância Terra-Sol; $\delta=$ declinação solar; $\omega_{\mathrm{s}}=$ ângulo do por-do-sol; $\varphi=$ latitude local.

Outros parâmetros do cálculo da $\lambda \mathrm{ET}$ foram determinados pelas expressões: 


$$
\Delta=\frac{4098 .\left(6,108 \exp \left(\frac{17,27 . \mathrm{t}_{\text {méd }}}{\mathrm{t}_{\text {méd }}+237,3}\right)\right)}{\left(\mathrm{t}_{\text {méd }}+237,3\right)^{2}}
$$

$\gamma=0,665 \cdot 10^{-3} \cdot \mathrm{Pa}$

$$
\rho \mathrm{a}=\frac{\mathrm{Pa}}{1.01 .\left(\mathrm{t}_{\text {méd. }}+273\right) \cdot 0,287}
$$

Tabela 1. Estações Meteorológicas Convencionais (EMC's) e suas respectivas informações de localização no Estado de Pernambuco. Fonte: INMET, 2014.

\begin{tabular}{cccccc}
\hline Cidade & Código & Latitude & Longitude & Altitude & Região \\
\hline Recife & 82900 & $8,05^{\circ} \mathrm{S}$ & $34,95^{\circ} \mathrm{W}$ & $10,00 \mathrm{~m}$ & Metropolitana \\
Garanhuns & 82893 & $8,88^{\circ} \mathrm{S}$ & $36,51^{\circ} \mathrm{W}$ & $882,76 \mathrm{~m}$ & Agreste \\
Surubim & 82789 & $7,83^{\circ} \mathrm{S}$ & $35,71^{\circ} \mathrm{W}$ & $418,32 \mathrm{~m}$ & Agreste \\
Caruaru & 82895 & $8,17^{\circ} \mathrm{S}$ & $35,58^{\circ} \mathrm{W}$ & $537,20 \mathrm{~m}$ & Agreste \\
Pesqueira & 82892 & $8,24^{\circ} \mathrm{S}$ & $36,46^{\circ} \mathrm{W}$ & $639,00 \mathrm{~m}$ & Agreste \\
Arcoverde & 82890 & $8,43^{\circ} \mathrm{S}$ & $37,05^{\circ} \mathrm{W}$ & $680,00 \mathrm{~m}$ & Sertão \\
Triunfo & 82789 & $7,81^{\circ} \mathrm{S}$ & $38,11^{\circ} \mathrm{W}$ & $1105,00 \mathrm{~m}$ & Sertão \\
Petrolina & 82797 & $9,38^{\circ} \mathrm{S}$ & $40,48^{\circ} \mathrm{W}$ & $370,46 \mathrm{~m}$ & São Francisco \\
Cabrobó & 82886 & $8,51^{\circ} \mathrm{S}$ & $39,33^{\circ} \mathrm{W}$ & $341,46 \mathrm{~m}$ & São Francisco \\
Floresta & 82887 & $8,36^{\circ} \mathrm{S}$ & $38,34^{\circ} \mathrm{W}$ & $309,70 \mathrm{~m}$ & São Francisco \\
\hline
\end{tabular}

Tabela 2. Dados climatológicos médios mensais de municípios do Estado de Pernambuco. Variáveis meteorológicas: $\mathrm{n}$ - brilho solar (em horas), $\mathrm{t}_{\text {méd. }}$ - temperatura média do ar (em $\left.{ }^{\circ} \mathrm{C}\right), \mathrm{UR}$ - umidade relativa

\begin{tabular}{|c|c|c|c|c|c|c|c|c|c|c|c|c|c|c|}
\hline Variáveis & Cidade & Jan & $\mathrm{Fev}$ & Mar. & Abr & Mai & Jun & Jul. & Ago. & Set & Out & Nov. & Dez & $\begin{array}{c}\text { Anu } \\
\text { al }\end{array}$ \\
\hline \multirow{10}{*}{$\mathrm{n}$} & Recife & 246 & 210 & 203 & 185 & 186 & 168 & 157 & 207 & 216 & 247 & 265 & 255 & 2550 \\
\hline & Garanhuns & 222 & 199 & 198 & 175 & 166 & 140 & 141 & 180 & 185 & 247 & 253 & 248 & 2358 \\
\hline & Surubim & 250 & 215 & 199 & 189 & 192 & 173 & 144 & 193 & 218 & 257 & 255 & 252 & 2536 \\
\hline & Caruaru & 234 & 204 & 213 & 196 & 185 & 159 & 168 & 219 & 218 & 271 & 257 & 252 & 2578 \\
\hline & Pesqueira & 228 & 202 & 206 & 186 & 176 & 150 & 155 & 200 & 202 & 259 & 255 & 250 & 2468 \\
\hline & Arcoverde & 246 & 209 & 228 & 217 & 204 & 177 & 196 & 258 & 251 & 294 & 262 & 255 & 2798 \\
\hline & Triunfo & 244 & 219 & 204 & 199 & 199 & 187 & 197 & 258 & 259 & 284 & 269 & 259 & 2778 \\
\hline & Petrolina & 238 & 217 & 224 & 217 & 232 & 221 & 233 & 263 & 263 & 257 & 253 & 237 & 2860 \\
\hline & Cabrobó & 241 & 205 & 207 & 200 & 200 & 192 & 197 & 227 & 245 & 271 & 270 & 247 & 2700 \\
\hline & Floresta & 246 & 220 & 223 & 211 & 202 & 176 & 196 & 253 & 245 & 284 & 279 & 259 & 2795 \\
\hline \multirow{15}{*}{$\mathrm{t}_{\text {méd. }}$} & Recife & 26,5 & 26,5 & 26,4 & 25,9 & 25,2 & 24,5 & 23,9 & 23,9 & 24,6 & 25,5 & 26,1 & 26,4 & 25,5 \\
\hline & Garanhuns & 22,0 & 22,0 & 21,9 & 21,4 & 20,3 & 19,2 & 18,4 & 18,4 & 19,3 & 20,8 & 21,7 & 21,9 & 20,6 \\
\hline & Surubim & 24,8 & 24,9 & 24,6 & 24,3 & 23,3 & 22,3 & 21,6 & 21,9 & 22,7 & 23,8 & 24,4 & 24,7 & 23,6 \\
\hline & Caruaru & 23,9 & 24,1 & 24,1 & 23,6 & 22,7 & 21,6 & 20,6 & 20,9 & 21,7 & 23,1 & 24,2 & 24,2 & 22,9 \\
\hline & Pesqueira & 24,4 & 24,1 & 24,0 & 23,2 & 22,0 & 20,8 & 20,2 & 20,4 & 21,7 & 23,2 & 24,1 & 24,2 & 22,7 \\
\hline & Arcoverde & 24,5 & 24,2 & 24,2 & 23,3 & 21,9 & 20,8 & 20,2 & 20,7 & 22,1 & 23,8 & 24,5 & 24,7 & 22,9 \\
\hline & Triunfo & 22,6 & 21,9 & 21,5 & 21,0 & 20,1 & 19,0 & 18,4 & 19,2 & 20,8 & 22,5 & 23,1 & 23,0 & 21,1 \\
\hline & Petrolina & 27,2 & 26,8 & 27,1 & 26,2 & 25,5 & 24,5 & 24,1 & 24,7 & 26,2 & 27,7 & 28,2 & 27,6 & 26,3 \\
\hline & Cabrobó & 27,0 & 26,5 & 26,4 & 25,6 & 24,8 & 24,0 & 23,7 & 24,5 & 26,0 & 27,9 & 28,4 & 27,7 & 26,0 \\
\hline & Floresta & 27,8 & 27,1 & 26,9 & 26,3 & 25,0 & 23,9 & 23,2 & 24,1 & 25,8 & 27,9 & 28,6 & 28,2 & 26,2 \\
\hline & Recife & 73,0 & 77,0 & 80,0 & 84,0 & 85,0 & 85,0 & 85,0 & 85,0 & 78,0 & 76,0 & 74,0 & 75,0 & 79,8 \\
\hline & Garanhuns & 76,8 & 74,4 & 81,0 & 85,1 & 88,0 & 90,1 & 91,6 & 88,8 & 81,3 & 77,8 & 71,9 & 74,7 & 81,8 \\
\hline & Surubim & 71,0 & 71,0 & 74,0 & 77,0 & 80,0 & 85,0 & 82,0 & 77,7 & 73,0 & 73,0 & 70,0 & 71,0 & 75,4 \\
\hline & Caruaru & 75,1 & 75,2 & 78,6 & 81,3 & 83,1 & 85,7 & 85,8 & 83,8 & 79,9 & 74,9 & 72,4 & 72,4 & 79,0 \\
\hline & Pesqueira & 66,7 & 68,7 & 73,2 & 78,5 & 81,4 & 83,1 & 82,2 & 76,3 & 71,7 & 66,5 & 63,9 & 65,4 & 73,1 \\
\hline
\end{tabular}
do ar (em \%) e u10 - velocidade do vento a 10 metros de altura $\left(\mathrm{m} \mathrm{s}^{-1}\right)$. Fonte: INMET, 2014.

Morais, J. E. F.; Silva; T. G. F.; Barbosa; M. L.; Diniz, W. J. S.; Souza, C. A. A.; Jardim, A. M. R. F.; Ferreira, J. M. S. 
Revista Brasileira de Geografia Física vol. 08, número especial (IV SMUD), (2015) 542-559.

\begin{tabular}{ccccccccccccccc}
\hline & Arcoverde & 62,0 & 66,0 & 71,0 & 74,0 & 74,0 & 76,0 & 77,0 & 74,0 & 68,0 & 65,0 & 64,0 & 64,0 & 69,6 \\
Triunfo & 67,4 & 72,9 & 79,2 & 83,0 & 82,9 & 84,1 & 81,3 & 72,4 & 65,9 & 60,0 & 60,0 & 62,7 & 72,7 \\
& Petrolina & 58,0 & 63,0 & 67,0 & 70,0 & 64,0 & 61,0 & 60,0 & 53,0 & 48,0 & 48,0 & 50,0 & 54,0 & 58,0 \\
& Cabrobó & 57,0 & 61,0 & 67,0 & 67,0 & 67,0 & 66,0 & 65,0 & 59,0 & 53,0 & 48,0 & 49,0 & 54,0 & 59,4 \\
& Floresta & 60,0 & 61,0 & 68,0 & 69,0 & 70,0 & 69,0 & 69,0 & 60,0 & 54,0 & 50,0 & 52,0 & 56,0 & 61,5 \\
\hline Recife & 2,33 & 2,33 & 2,33 & 2,33 & 2,33 & 2,33 & 2,33 & 2,33 & 2,33 & 2,33 & 2,33 & 2,33 & 2,33 \\
u10 & Garanhuns & 3,20 & 3,20 & 3,20 & 3,20 & 3,20 & 3,20 & 3,20 & 3,20 & 3,20 & 3,20 & 3,20 & 3,20 & 3,20 \\
& Surubim & 3,16 & 3,16 & 3,16 & 3,16 & 3,16 & 3,16 & 3,16 & 3,16 & 3,16 & 3,16 & 3,16 & 3,16 & 3,16 \\
& Caruaru & 2,76 & 2,76 & 2,76 & 2,76 & 2,76 & 2,76 & 2,76 & 2,76 & 2,76 & 2,76 & 2,76 & 2,76 & 2,76 \\
& Pesqueira & 3,50 & 4,00 & 3,55 & 3,27 & 3,34 & 3,52 & 3,97 & 4,24 & 4,64 & 4,07 & 3,78 & 3,48 & 3,77 \\
& Arcoverde & 4,02 & 4,27 & 4,08 & 3,58 & 2,98 & 2,84 & 3,23 & 3,38 & 4,29 & 4,43 & 4,37 & 3,87 & 3,78 \\
& Triunfo & 2,97 & 3,72 & 3,01 & 2,95 & 3,70 & 4,28 & 4,70 & 5,11 & 5,01 & 3,37 & 3,24 & 3,15 & 3,77 \\
& Petrolina & 2,41 & 2,73 & 2,31 & 2,36 & 2,80 & 3,30 & 3,76 & 4,07 & 4,04 & 3,25 & 2,87 & 2,69 & 3,04 \\
& Cabrobó & 3,50 & 3,50 & 3,50 & 3,50 & 3,50 & 3,50 & 3,50 & 3,50 & 3,50 & 3,50 & 3,50 & 3,50 & 3,50 \\
& Floresta & 1,81 & 1,71 & 1,56 & 1,66 & 1,95 & 2,36 & 2,68 & 2,88 & 2,96 & 2,75 & 2,38 & 2,01 & 2,23 \\
\hline
\end{tabular}

$\mathrm{cp}=\frac{\gamma \cdot 0,622 \cdot 2,45}{\mathrm{~Pa}}$

sendo, $\mathrm{Pa}=$ pressão atmosférica do $\operatorname{ar}(\mathrm{kPa})$, estimada pela equação:

$\mathrm{Pa}=101,3 \cdot\left(\frac{293-0,0065 \cdot \mathrm{ALT}}{293}\right)^{5,26}$

em que, $\mathrm{ALT}=\mathrm{a}$ altitude local $(\mathrm{m})$.

Para conversão dos dados de velocidade do vento obtidos a $10 \mathrm{~m}$ para a altura padrão de $2 \mathrm{~m}$ acima de uma superfície gramada foi utilizada a seguinte equação:

$\mathrm{u}_{2}=\mathrm{u}_{\mathrm{z}}\left(\frac{4,87}{\ln (67,8 \mathrm{z}-5,42)}\right)$

onde $\mathrm{u}_{\mathrm{z}}=$ velocidade obtida na estação meteorológica automática $\left(\mathrm{m} \mathrm{s}^{-1}\right) ; \mathrm{z}=$ altura de medição de velocidade de vento $(3 \mathrm{~m})$.

$$
\begin{aligned}
& \mathrm{e}_{\mathrm{s}}=\left(\frac{0,6108 \cdot \exp \left(17,27 \mathrm{t}_{\text {méd }}\right)}{\mathrm{t}_{\text {méd }}+237,3}\right) \\
& \mathrm{e}_{\mathrm{a}}=\frac{\mathrm{UR}_{\text {méd }}}{100} \cdot \mathrm{e}_{\mathrm{s}}
\end{aligned}
$$

onde, $\mathrm{UR}_{\text {méd }}=$ umidade relativa do ar (calculada pelos valores máximos e mínimos diários).

A $r_{a}$ é a resistência que a cultura oferece ao fluxo do vapor d'água entre a superfície foliar e atmosfera, sendo esta estimada pelo modelo proposto por Brutsaert e Stricker (1979): $r_{a}=\frac{\ln [(Z m-d) / Z o m] \cdot \ln \left((Z h-d) / z_{o h}\right)}{K^{2} u_{z}}$

onde $\mathrm{d}=$ deslocamento do plano zero da altura (m), sendo igual a $2 / 3$ da altura de colheita $\left(\mathrm{h}_{\mathrm{c}}=\right.$ $0,12 \mathrm{~m}) ; Z_{\mathrm{om}}=$ comprimento de rugosidade para o momento da transferência $(0.123 \times \mathrm{x} \mathrm{hc})$; $\mathrm{Z}_{\mathrm{oh}}=$ comprimento de rugosidade para o calor $\mathrm{e}$ transferência de vapor de água $\left(0.1 \times Z_{\mathrm{om}}\right) ; \mathrm{K}=$ constante de von Karman $(0,41) ; \mathrm{u}_{\mathrm{z}}=$ velocidade do vento na altura $z$. Para obtenção da $r_{s}$ foi utilizada a seguinte expressão:

$$
\mathrm{r}_{\mathrm{S}}=\frac{\mathrm{r}_{\mathrm{i}}}{\operatorname{IAF}_{\text {ativo }}}
$$

sendo, $r_{i}=$ resistência dos estômatos da folha bem iluminada (assumindo $100 \mathrm{~m} \mathrm{~s}^{-1}$ ); $\mathrm{IAF}_{\text {ativo }}=$ índice de área foliar que contribui efetivamente para o troca de calor e vapor entre a superfície foliar e atmosfera. Monteith (1965) propôs a redução deste valor pela metade:

$$
\mathrm{IAF}_{\mathrm{ativo}}=\mathrm{IAFx} 0,5
$$

onde, IAF = o índice de área foliar, sendo função de $\mathrm{h}$ (altura da cultura da grama, 0,12 m), com $\mathrm{IAF}=24 \times \mathrm{h}$.

Os dados de $\lambda E T$ foram calculados com os dados climáticos mensais, e em seguida, multiplicado pelo número de dia de cada mês para obtenção dos valores acumulados.

Cenários futuros de mudanças climáticas

Foram simulados três cenários de mudanças climáticas para cada uma das culturas: Cenário Atual - a evapotranspiração de referência foi 
obtida somente com base nas normais climatológicas; Cenário B2 - considerou-se o efeito do incremento de $1,8^{\circ} \mathrm{C}$ da temperatura na duração do ciclo e na demanda de água; Cenário A1F1 - considerou-se o efeito do incremento de $4,0^{\circ} \mathrm{C}$ da temperatura na duração do ciclo e na demanda de água. Para ambos cenários, B2 e $\mathrm{A} 1 \mathrm{~F} 1$, foi considerada uma redução de $5,0 \%$ nos valores absolutos da umidade relativa do ar, incremento do $\mathrm{CO}_{2}\left(900 \mu \mathrm{mol} \mathrm{mol}{ }^{-1}\right)$, conforme citado por Lovelli et al. (2010), promovendo uma redução média de $22 \%$ da condutância estomática de uma folha bem iluminada $\left(\mathrm{r}_{1}\right)$ e um aumento de $4 \%$ no IAF. Ambas as anomalias da temperatura e umidade relativa do ar referem-se às projeções oriundas do modelo acoplado do Hadley Centre for Climate Prediction and Research, da Inglaterra (HadCM3). Foram simulados todos os ciclos possíveis durante um ano (janeiro a março, fevereiro a abril, março a maio, abril a junho, maio a julho, junho a agosto, julho a setembro, agosto a outubro, setembro a novembro, outubro a dezembro, novembro a janeiro), assumindo a data de plantio o primeiro dia de cada mês e a colheita quando a cultura do sorgo forrageiro atingisse $1574{ }^{\circ} \mathrm{C}$ dia e o feijão-caupi $1261,7{ }^{\circ} \mathrm{C}$ dia. Não foram considerados os efeitos do déficit hídrico, assim assumiu-se que o ciclo de cultivo foi conduzido em condições de plena disponibilidade hídrica, independentemente do período do ano.

\section{Resultados e Discussão}

Nas Figuras de 1 e 2, e 3 e 4, podem ser observadas as durações do ciclo e demanda acumulada de água do sorgo forrageiro e do Recife

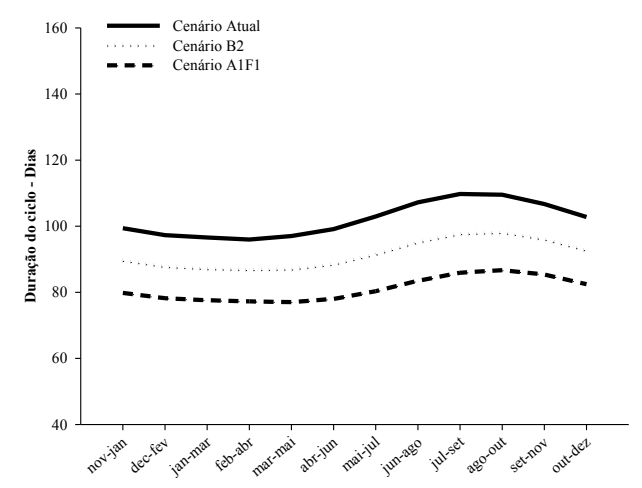

feijão-caupi, respectivamente, considerando todos os possíveis ciclos de cultivo no período de um ano, para o cenário atual e futuro (B2 e A1F1). De modo geral, a duração do ciclo e a demanda de água dependem da localização geográfica da área de cultivo e as mesmas tenderam a reduzir, independentemente do mês de início da simulação para ambas as culturas, com a inserção dos cenários de mudanças climáticas.

Percebe-se, para o cenário atual (Figuras 1 e 3), que as menores durações do ciclo ocorrem nos municípios situados na região do Semiárido pernambucano (sorgo forrageiro: Floresta -85 a 109 dias, Cabrobó - 86 a 107 dias e Petrolina - 86 a 102 dias; feijão-caupi: Floresta - 68 a 90 dias, Cabrobó - 69 a 88 dias e Petrolina - 69 a 85 dias), onde as maiores magnitudes da temperatura do ar favorecem o desenvolvimento mais acelerado das culturas. Em Recife, em que o fator altitude tem pouco efeito sobre o regime térmico local, porém sofre influência reguladora do oceano, devido a sua localização litorânea, as durações dos ciclos podem variar de 96 a 110 dias para o sorgo forrageiro, e de 77 a 89 dias para o feijão-caupi. Por outro lado, nos municípios de Triunfo e Garanhuns, onde a temperatura do ar é mais amena, as culturas tendem a apresentar maiores durações do ciclo de 122 a 132 dias e 119 a 132 dias para o sorgo forrageiro, e de 96 a 120 dias e 96 a 118 dias para o feijão-caupi. Os demais locais, possuem durações intermediarias para $\mathrm{o}$ sorgo forrageiro, com intervalos de 102 a 132 dias em Arcoverde, de 98 a 131 dias em Surubim, de 106 a 132 dias em Caruaru e de 103 a 132 dias em Pesqueira. O mesmo podendo ser

Surubim

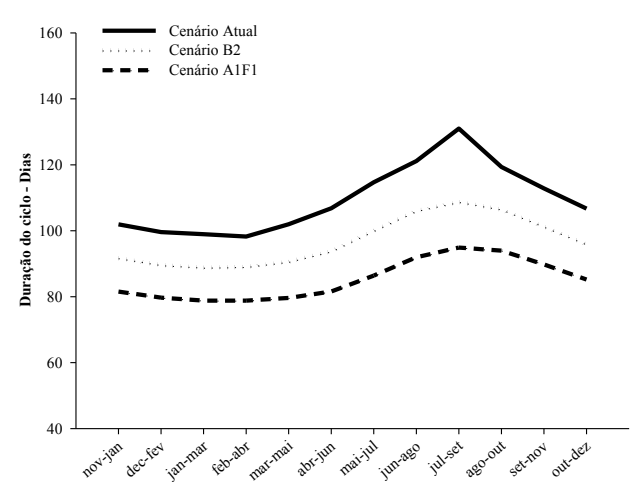


Revista Brasileira de Geografia Física vol. 08, número especial (IV SMUD), (2015) 542-559.

Caruaru

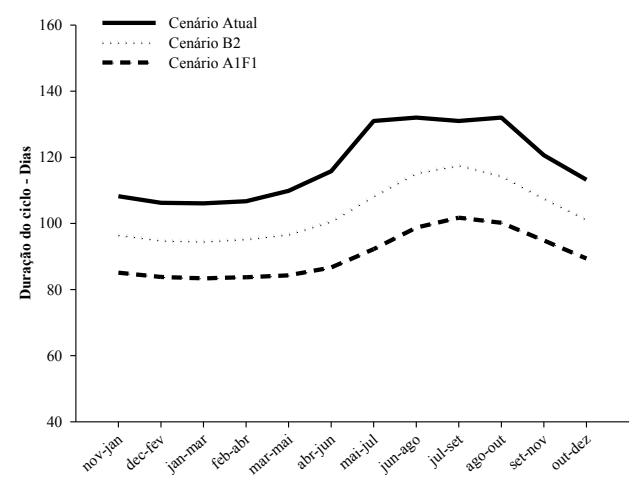

Pesqueira

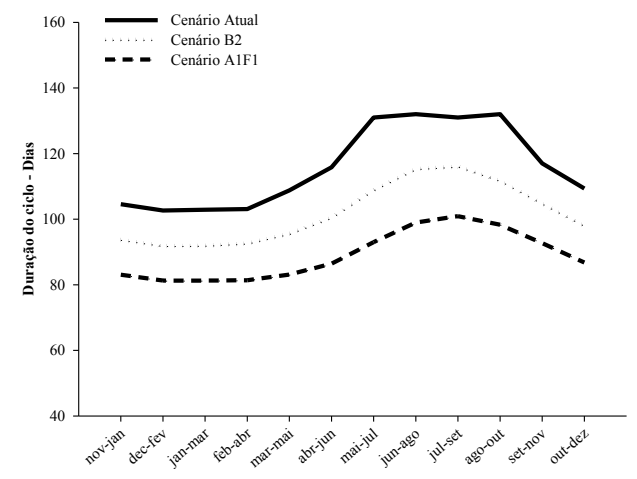

Triunfo

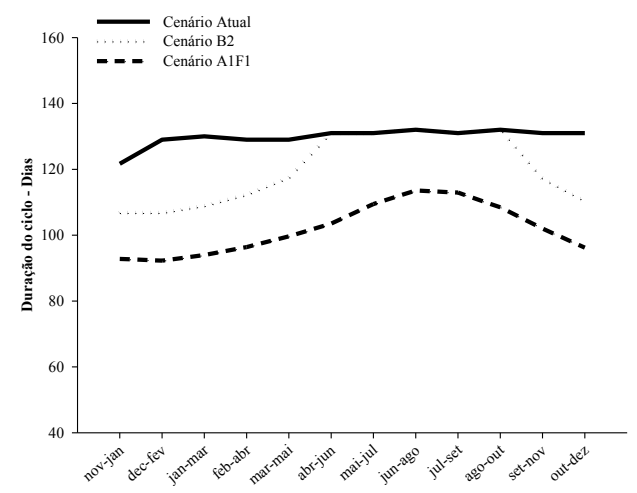

Cabrobó

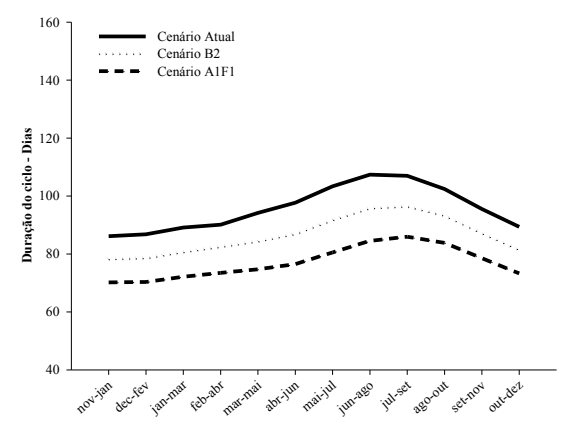

Garanhuns

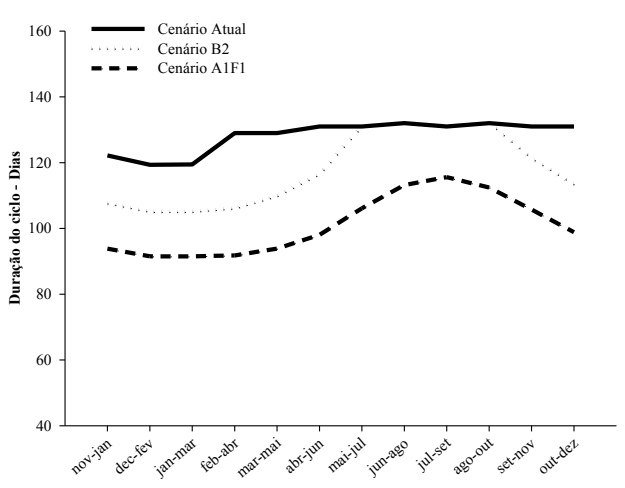

Arcoverde

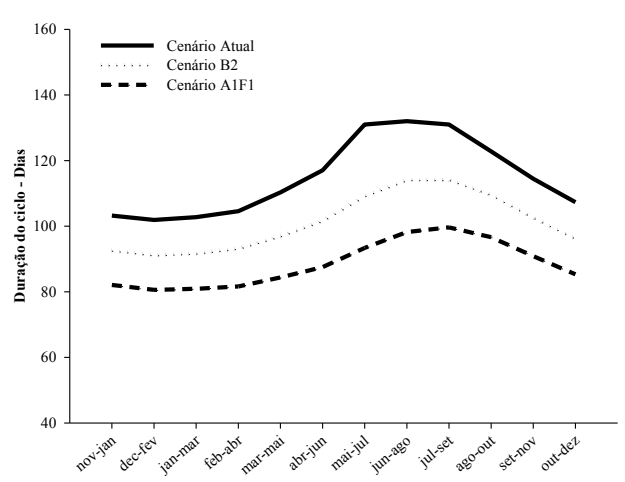

Floresta

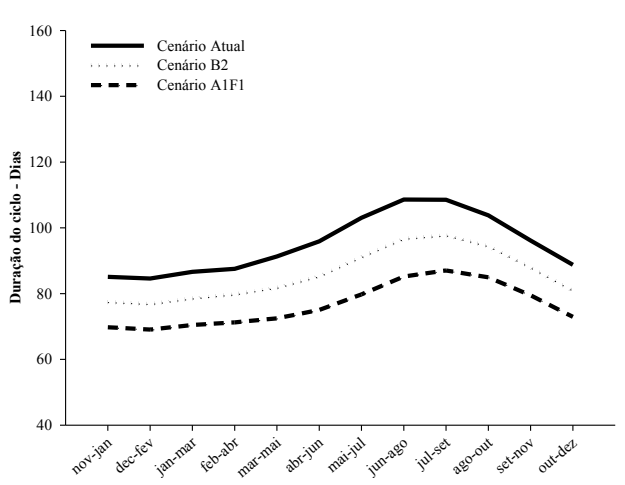

Petrolina

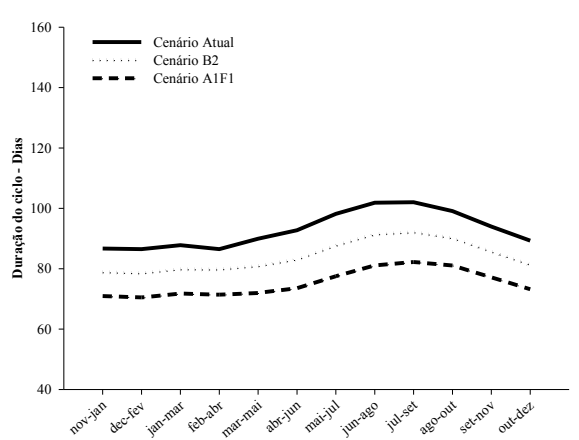

Figura 1. Duração do ciclo do sorgo forrageiro cultivado nos municípios Recife, Surubim, Caruaru, Garanhuns, Pesqueira, Arcoverde, Triunfo, Floresta, Cabrobó e Petrolina no cenário Atual; Cenário B2: $+1,8^{\circ} \mathrm{C},-5,0 \%$ da $\mathrm{UR}_{\mathrm{ar}}$ e incremento de $\mathrm{CO}_{2}$ na duração do ciclo e demanda de água; Cenário $\mathrm{A} 1 \mathrm{~F} 1:+4,0^{\circ} \mathrm{C}$, $-5,0 \%$ da $\mathrm{UR}_{\mathrm{ar}}$ e incremento de $\mathrm{CO}_{2}$ na duração do ciclo e demanda de água. 
observado para o feijão caupi (de 82 a 104 dias em Arcoverde, de 79 a 99 dias em Surubim, de 85 a 107 dias em Caruaru e de 82 a 106 dias em Pesqueira).

Com os cenários de mudanças climáticas da temperatura do ar, os municípios de Floresta, Cabrobó e Petrolina apresentaram, em média, reduções de $10 \%(86 \pm 8$ dias, $86 \pm 7$ dias e $84 \pm 5$ dias, nessa ordem) e de $8 \%$ ( $73 \pm 7$ dias, $73 \pm 6$ dias e $71 \pm 5$ dias, nessa ordem) na duração do ciclo do sorgo forrageiro e do feijão-caupi, respectivamente, quando se considerou o cenário mais otimista B2.

Mas, essa diminuição atingiu magnitudes de $20 \%$ ( $76 \pm 7$ dias), $20 \%$ ( $77 \pm 6$ dias) e $19 \%$ (75 \pm 4 dias) para o sorgo forrageiro, e de $16 \%$

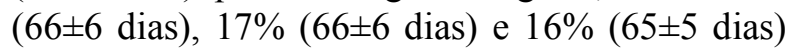
para o feijão-caupi, quando foi assumido o cenário mais pessimista A1F1.

Em Recife, com o regime térmico médio semelhante aos dos municípios do Semiárido, a duração média do ciclo reduziu de $10 \%(91 \pm 4$ dias) e $21 \%$ ( $81 \pm 4$ dias) para o sorgo forrageiro, e passou para $76 \pm 4$ dias (B2) e $68 \pm 4$ dias (A1F1), ou seja, uma redução média de $9 \%$ e $18 \%$ em relação ao cenário atual para o feijão-caupi. Nos municípios de Triunfo e Garanhuns, mesmo com o fator altitude, que induz a temperaturas mais amenas, observou-se, para os ciclos reduções percentuais próximas às observadas para os municípios antes citados. Nesses dois locais, a diminuição da duração do ciclo para o sorgo forrageiro foi de $8 \%$ (B2) e $22 \%$ (A1F1) e $8 \%$ (B2) e $21 \%$ (A1F1), nessa ordem, enquanto para o feijão-caupi foi de $11 \%$ (B2) e $21 \%$ (A1F1) e $8 \%$ (B2) e 19\% (A1F1).

Esses resultados estão associados ao efeito que a temperatura poderá promover no desenvolvimento das plantas, que é reflexo de processos essenciais como manutenção térmica do dossel, fotossíntese e respiração. Porém, essa influência dependerá do tipo de espécie, logo que plantas com diferentes metabolismos fotossintéticos responderão de maneira diferente ao aumento térmico no ambiente, e da disponibilidade hídrica, resultando assim em modificações no desempenho produtivo das culturas (Beltrão, 2008).
Com o aumento da temperatura no ambiente espera-se modificações dos parâmetros fisiológicos das culturas, como fotossíntese, transpiração, temperatura foliar e potencial de água na folha.

Contudo, essas respostas podem ser diferentes dependendo do efeito conjunto entre o nível de $\mathrm{CO}_{2}$ e outros fatores ambientais, do tipo de processo fotossintético, bem como das alterações da arquitetura e mecanismos das plantas (Ainsworth e Rogers, 2007).

Em geral, o processo fotossintético das plantas $\mathrm{C} 3$ responderá melhor à elevada $\left[\mathrm{CO}_{2}\right]$ quando comparada às plantas C4 (Beltrão, 2008). Isto ocorre primeiramente por que dentro das células guardas das plantas $\mathrm{C} 4$ os níveis de $\mathrm{CO}_{2}$ são próximo da saturação e a fotorrespiração é praticamente ausente. Apesar disso, tem-se comprovado que sob condições de disponibilidade de água e alta $\left[\mathrm{CO}_{2}\right]$ as plantas tendem a aumentar a taxa de assimilação de $\mathrm{CO}_{2}$, o que pode está relacionado com melhorias nas relações hídricas das espécies por causa do aumento da $\left[\mathrm{CO}_{2}\right]$ no ambiente (Ghannoum et al., 2000; Urban et al., 2002). Porém, a resposta à elevada $\left(\left[\mathrm{CO}_{2}\right]\right)$ dependerá da temperatura do ambiente de cultivo, como verificado por $\mathrm{Vu}$ (2005), em que plantas de amendoim (C3) sob alta concentração de $\mathrm{CO}_{2}$ $\left(720 \mu \mathrm{mol} \mathrm{m} \mathrm{m}^{-2} \mathrm{~s}^{-1}\right)$ e de temperatura do ar $(1,5 \mathrm{e}$ $\left.6,0 \quad{ }^{\circ} \mathrm{C}\right)$, apresentaram um aumento do desempenho da atividade fotossintética das plantas, como resultado do incremento do conteúdo (5-12\%) e da atividade da enzima Rubisco (9-20\%).

Uma maior proporção de $\mathrm{CO}_{2}$ na atmosfera tem $\mathrm{o}$ potencial de aumentar a atividade fotossintética e diminuir a fotorrespiração pela diminuição da atividade de oxigenase da Rubisco (Raven et al., 2014). No entanto, em espécies C3, como é o caso do feijão-caupi, sob altas temperaturas a fotorrespiração é tida como um processo de autodefesa do aparelho fotossintético. Além disso, as plantas C3 aumentam a taxa de fotossíntese até temperaturas de aproximadamente $30^{\circ} \mathrm{C}$, acima desse valor pode acarretar em degeneração de enzimas importantes do processo fotossintético da planta (Taiz e Zeiger, 2009). 
Revista Brasileira de Geografia Física vol. 08, número especial (IV SMUD), (2015) 542-559.

Recife

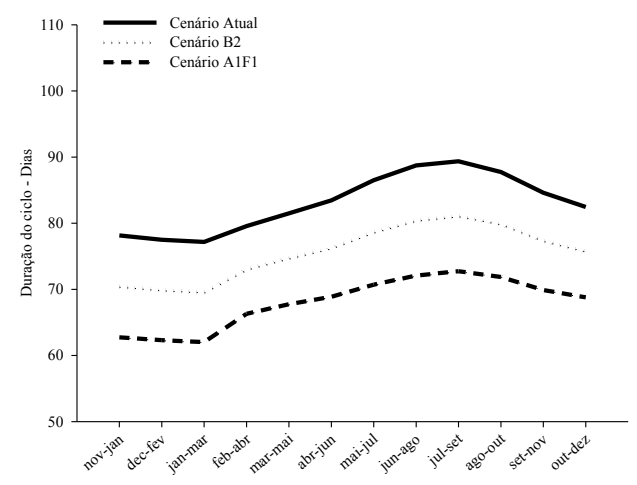

Caruaru

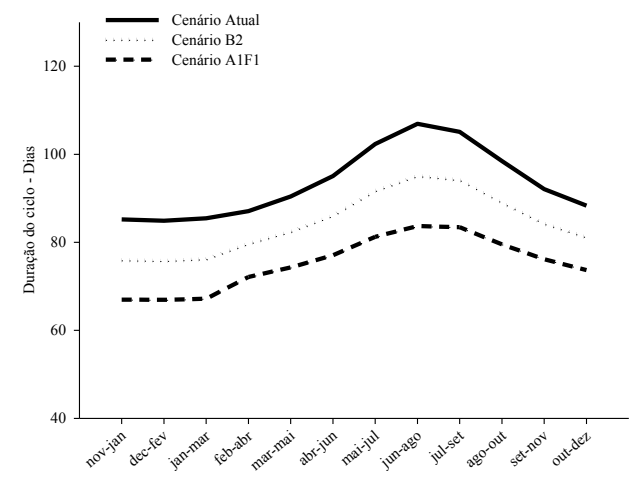

Pesqueira

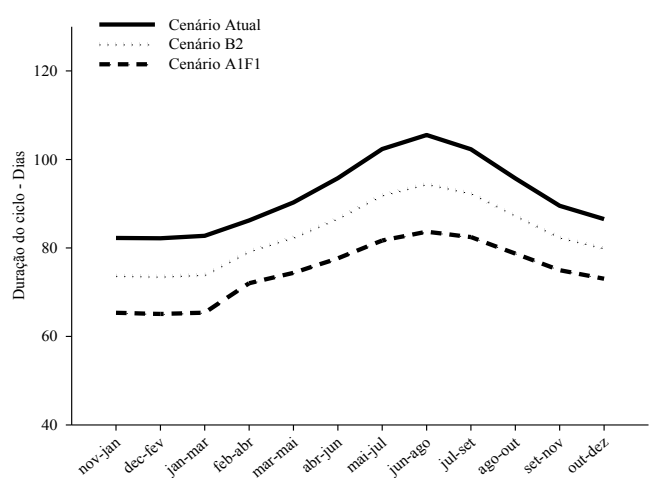

Triunfo

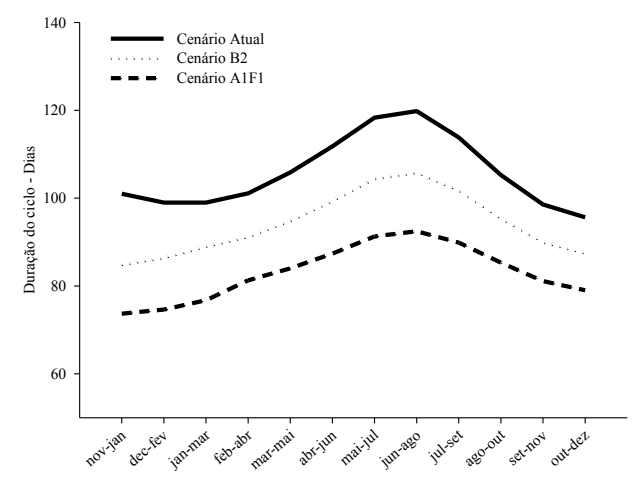

Cabrobó
Surubim

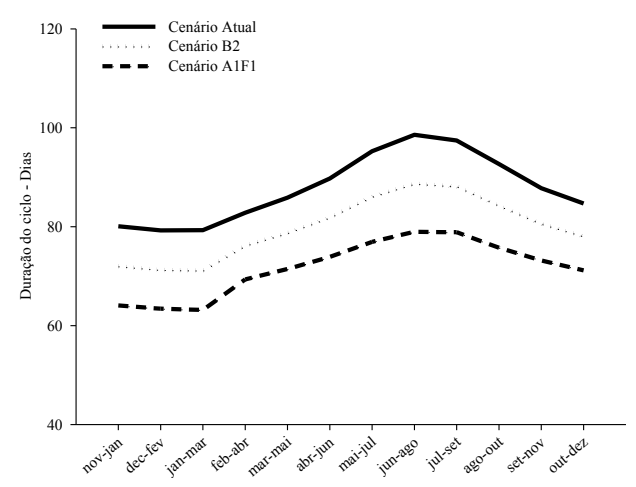

Garanhuns

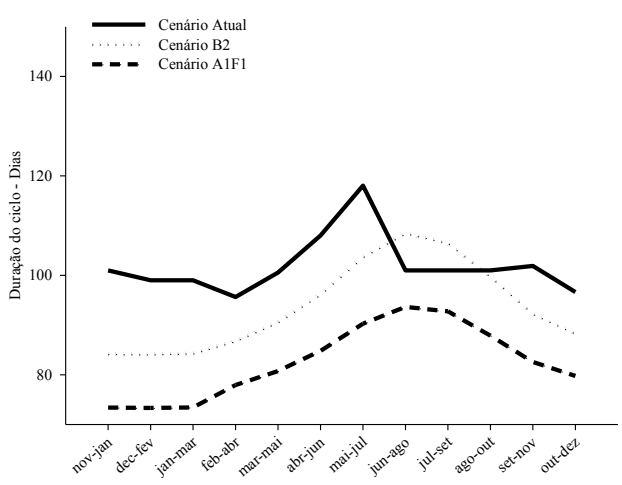

Arcoverde

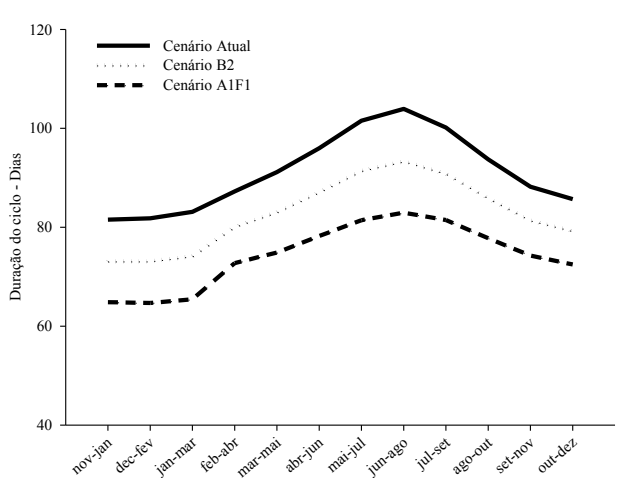

Floresta

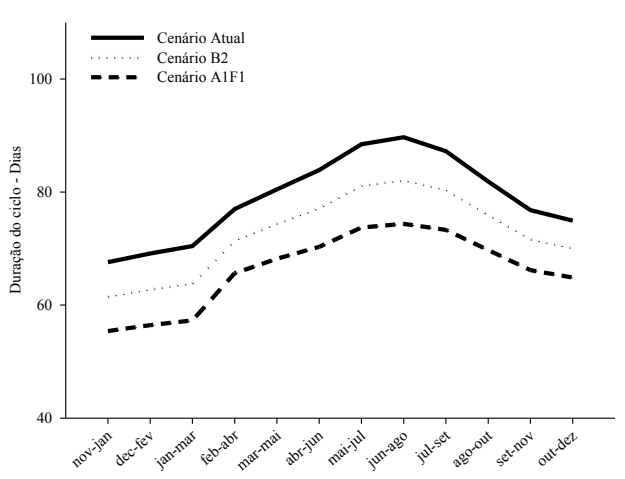

Petrolina 

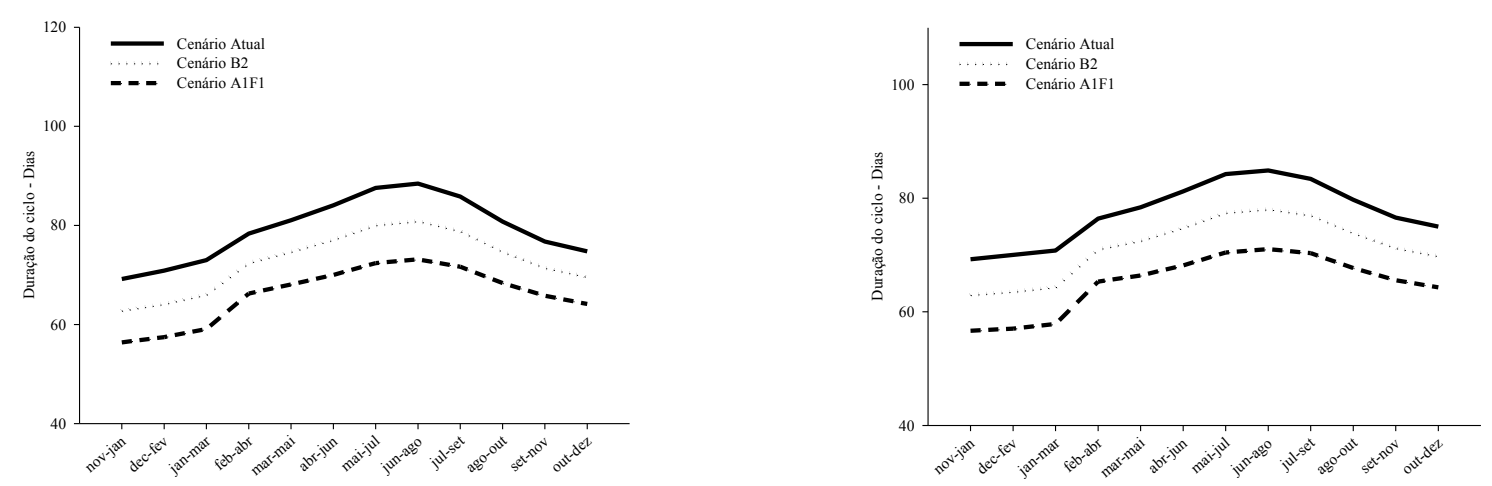

Figura 2. Duração do ciclo do feijão-caupi cultivado nos municípios Recife, Surubim, Caruaru, Garanhuns, Pesqueira, Arcoverde, Triunfo, Floresta, Cabrobó e Petrolina no cenário Atual; Cenário $\mathrm{B} 2:+1,8^{\circ} \mathrm{C},-5,0 \%$ da $\mathrm{UR}_{\mathrm{ar}}$ e incremento de $\mathrm{CO}_{2}$ na duração do ciclo e demanda de água; Cenário $\mathrm{A} 1 \mathrm{~F} 1:+4,0^{\circ} \mathrm{C},-5,0 \%$ da $\mathrm{UR}_{\mathrm{ar}}$ e incremento de $\mathrm{CO}_{2}$ na duração do ciclo e demanda de água.

Para todos os municípios e ambas as espécies, verificou-se a sazonalidade de resposta da duração do ciclo da cultura, em função da inserção dos cenários de mudanças climáticas, logo que o regime térmico intra-anual comumente apresenta variações em decorrência da localização dos mesmos em relação à linha imaginária do Equador. Todavia, o efeito de continentalidade e relevo podem ser determinantes nas magnitudes das reduções esperadas com o aumento da temperatura do ar, e consequentemente, no processo de evapotranspiração das culturas.

Em relação à demanda de água das culturas (Figura 3 e 4), no cenário atual a ETc é inferior nos municípios em que a duração do ciclo é mais reduzida (sorgo forrageiro: Floresta - $310 \pm 40$ $\mathrm{mm}$, Cabrobó - 365 $\pm 52 \mathrm{~mm}$ e Petrolina $-319 \pm 38$ $\mathrm{mm}$; feijão-caupi: Floresta - $362 \pm 38 \mathrm{~mm}$, Cabrobó - 419 $\pm 51 \mathrm{~mm}$ e Petrolina - 370 $\pm 36 \mathrm{~mm}$ ). Cabrobó foi o que apresentou maiores valores da ETc para o sorgo forrageiro, e feijão-caupi, dentre àqueles municípios avaliados. Em Recife, a demanda de água é ainda menor quando comparada a esses municípios (em média, 276 $\mathrm{mm}$ por ciclo para o sorgo forrageiro; $312 \mathrm{~mm}$ por ciclo para o feijão-caupi), mesmo apresentando regime térmico semelhante; isso por que possui valores de umidade relativa do ar mais elevados. Nos municípios de Triunfo (em média, 368 70 $\mathrm{mm}$ por ciclo para o sorgo forrageiro; $413 \pm 56 \mathrm{~mm}$ por ciclo para o feijão-caupi) e Garanhuns (em média, $307 \pm 65 \mathrm{~mm}$ por ciclo para o sorgo forrageiro; $340 \pm 72 \mathrm{~mm}$ por ciclo para o feijãocaupi), os consumos de água das culturas apresentaram resultados bastante distintos entre si, mesmo com condição térmica parecida. Em Garanhuns apesar da temperatura do ar ser próxima àquela de Triunfo, a umidade relativa do ar é bem superior, o que induziu as demandas hídricas inferiores para ambas as culturas. Para os demais municípios, as magnitudes da ETc foram superiores para Arcoverde (em média, 361 \pm 39 $\mathrm{mm}$ para o sorgo forrageiro; $400 \pm 45 \mathrm{~mm}$ por ciclo para o feijão-caupi), seguida de Pesqueira (em média, $350 \pm 47 \mathrm{~mm}$ para o sorgo forrageiro; $386 \pm 49 \mathrm{~mm}$ por ciclo para o feijão-caupi), Surubim (em média, $319 \pm 40 \mathrm{~mm}$ para o sorgo forrageiro; $356 \pm 41 \mathrm{~mm}$ por ciclo para o feijãocaupi), Caruaru (em média, $306 \pm 40 \mathrm{~mm}$ para o sorgo forrageiro; $338 \pm 43 \mathrm{~mm}$ por ciclo para o feijão-caupi).

Com os cenários de mudanças climáticas, em Recife a demanda de água passou para $263 \pm 42$ $\mathrm{mm}$ (B2) e $249 \pm 41 \mathrm{~mm}$ (A1F1) para o sorgo forrageiro, promovendo redução média na ordem de 5 e $10 \%$, respectivamente. Enquanto, passou para $302 \pm 42 \mathrm{~mm}(\mathrm{~B} 2)$ e $290 \pm 40 \mathrm{~mm}$ (A1F1) para o feijão-caupi, promovendo redução média na ordem de 3 e 7\%, respectivamente. Nos municípios de Cabrobó (cenário B2 - 358 $\pm 53 \mathrm{~mm}$ para o sorgo forrageiro; $418 \pm 52 \mathrm{~mm}$ por ciclo para o feijão-caupi; cenário A1F1 - $348 \pm 56 \mathrm{~mm}$ para o sorgo forrageiro; $414 \pm 56 \mathrm{~mm}$ por ciclo para o feijão-caupi), Petrolina (cenário B2 $308 \pm 38 \mathrm{~mm}$ para o sorgo forrageiro; $363 \pm 37 \mathrm{~mm}$ por ciclo para o feijão-caupi; cenário A1F1 $298 \pm 40 \mathrm{~mm}$ para o sorgo forrageiro; $357 \pm 40 \mathrm{~mm}$ por ciclo para o feijão-caupi) e Floresta (cenário B2 - 302 $\pm 41 \mathrm{~mm}$ para o sorgo forrageiro; $356 \pm 38$ $\mathrm{mm}$ por ciclo para o feijão-caupi; cenário A1F1 $291 \pm 43 \mathrm{~mm}$ para o sorgo forrageiro; $349 \pm 41 \mathrm{~mm}$ por ciclo para o feijão-caupi) as reduções nas demandas de água foram, em média, menores do que as observadas em Recife. No município de Triunfo, a demanda de água foi de $363 \pm 46 \mathrm{~mm}$ ($1 \%$, B2) e $334 \pm 47 \mathrm{~mm}(-9 \%$, A1F1) para o sorgo 
forrageiro e de $397 \pm 48 \mathrm{~mm}(-4 \%$, B2) e $379 \pm 48$ $\mathrm{mm}(-8 \%, \mathrm{~A} 1 \mathrm{~F} 1)$ para o feijão caupi, porém nos meses mais frios houve uma tendência de aumento da demanda de água. O mesmo foi verificado em Garanhuns, onde a ETc foi de $300 \pm 48 \mathrm{~mm}(-2 \%$, B2) e $276 \pm 48 \mathrm{~mm}(-10 \%$, A1F1) para o sorgo forrageiro e de $332 \pm 50 \mathrm{~mm}$ ($2 \%, \mathrm{~B} 2)$ e $313 \pm 49 \mathrm{~mm}(-8 \%$, A1F1) para o feijãocaupi. Esses resultados estão associados ao fato da duração do ciclo não ter sido reduzido expressivamente nesse período, e o déficit de pressão de vapor ter apresentado valores maiores. Nos demais municípios, os cenários de mudanças climáticas também resultaram reduções nas demandas de água, sendo mais expressivas em Caruaru (cenário B2: -6\% para o sorgo forrageiro; $-4 \% \mathrm{~mm}$ para o feijão-caupi; cenário A1F1: $-12 \%$ para o sorgo forrageiro; $-8 \%$ para o feijão-caupi), seguido de Pesqueira (cenário B2: $-4 \%$ para o sorgo forrageiro; $-2 \% \mathrm{~mm}$ para o feijão-caupi; cenário A1F1: $-9 \%$ para o sorgo forrageiro; $-5 \%$ para o feijão-caupi), Arcoverde (cenário B2: $-4 \%$ para o sorgo forrageiro; $-2 \% \mathrm{~mm}$ para o feijãocaupi; cenário A1F1: -9\% para o sorgo forrageiro; $-4 \%$ para o feijão-caupi) e Surubim (cenário B2: $3 \%$ para o sorgo forrageiro; $-1 \%$ para o feijãocaupi; cenário A1F1: -8\% para o sorgo forrageiro; $-4 \%$ para o feijão-caupi).

Esses resultados induz inferir que, o efeito da temperatura do ar sobre a duração do ciclo e do $\mathrm{CO}_{2}$ na atividade estomática, apresentam maior efeito do que o aumento do déficit de pressão de

\section{Caruaru}

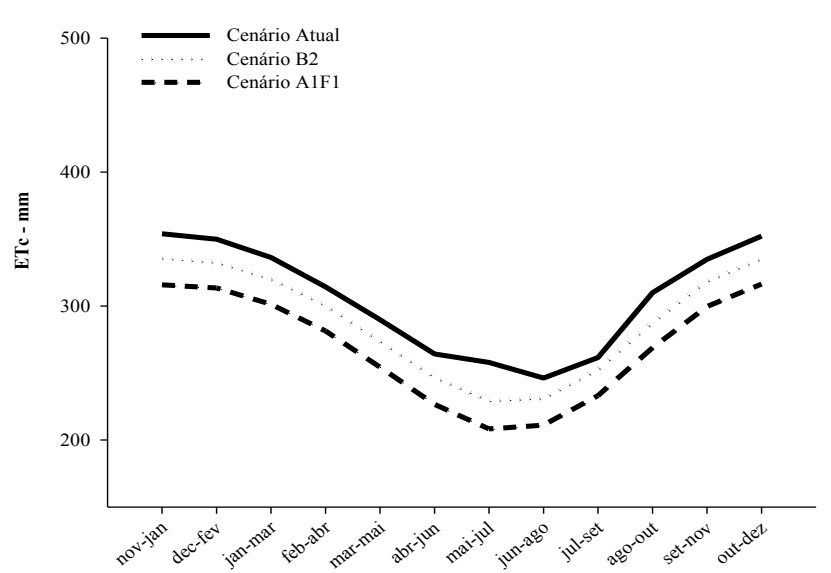

vapor d'água e o aumento do índice de área foliar das plantas. Todavia, as informações quanto os efeitos das mudanças climáticas sobre a demanda de água pelas culturas, ainda são bastante contraditórias. Gondim et al. (2011) avaliaram os impactos das mudanças climáticas na demanda de água para irrigação de culturas perenes, na Bacia do Jaguaribe, no Estado do Ceará, e verificaram que as mudanças climáticas projetadas aumentarão a demanda de água para irrigação, devido ao aumento da evapotranspiração e redução da precipitação pluvial. Contudo, os autores não destacam o efeito da temperatura do ar na resposta fisiológica das plantas.

Segundo Lloyd e Fanquhar (2008) esta redução da demanda de água da cultura pode estar mais associada com a redução da condutância estomática das plantas em resposta ao déficit de pressão de vapor d'água. Vários estudos têm constatado a redução da evapotranspiração das culturas por causa do aumento das concentrações de $\mathrm{CO}_{2}$ que tenderam a reduzir a transpiração das plantas (Wall et al., 2001). Contudo, ainda existem incertezas devido ao aumento de produtividade induzir o incremento da área foliar, que pode favorecer um aumento da transpiração e da evapotranspiração das culturas, contrariando as possibilidades de redução da condutância estomática (Magliulo et al., 2003). Por outro lado, estas respostas dependem da existência ou não de fatores estressantes no ambiente de cultivo.

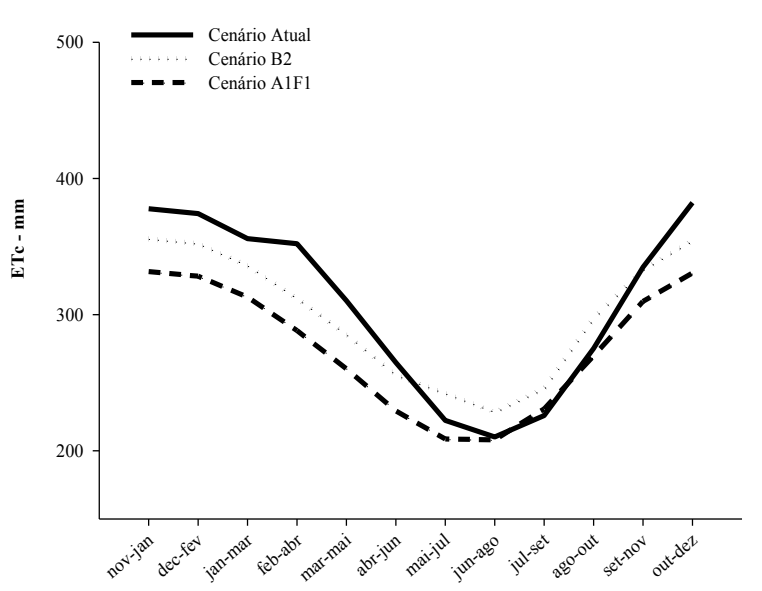


Pesqueira

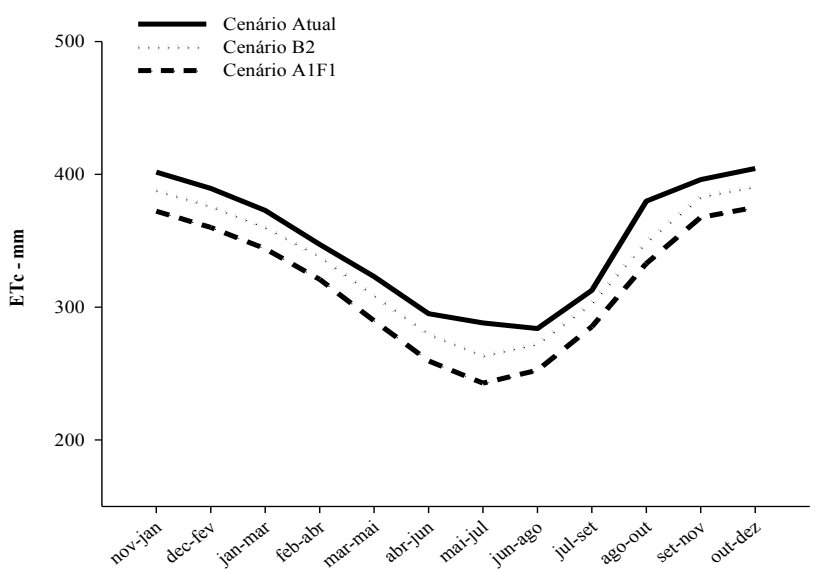

Triunfo

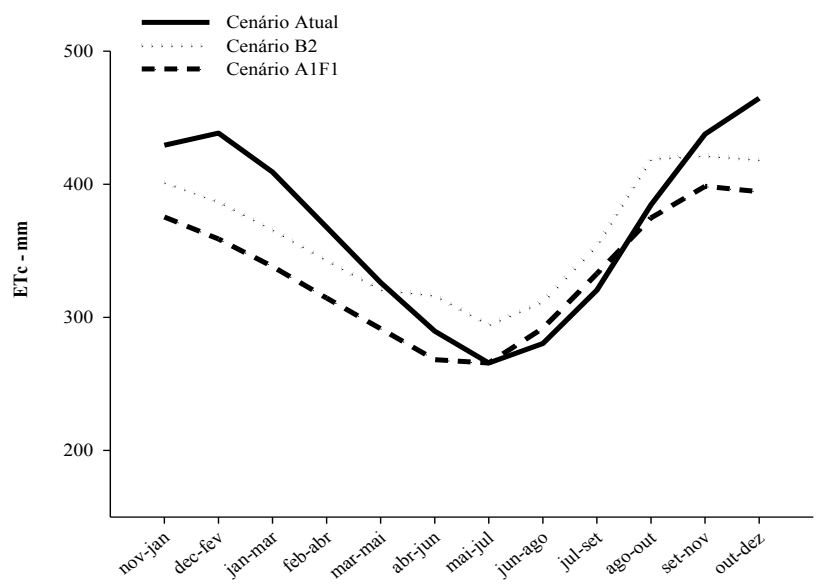

Cabrobó

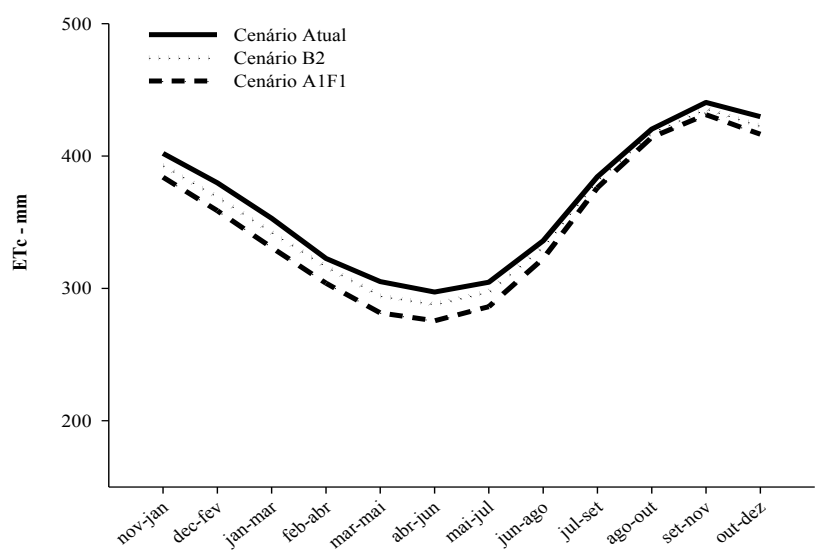

Arcoverde

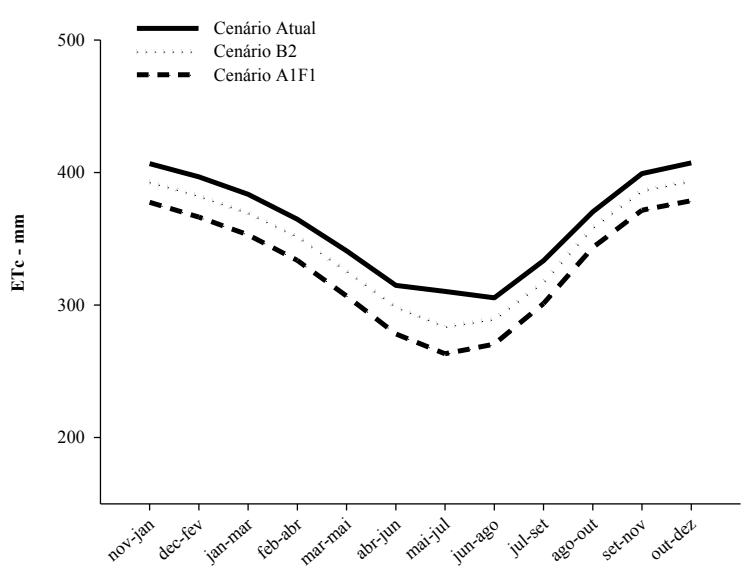

Floresta

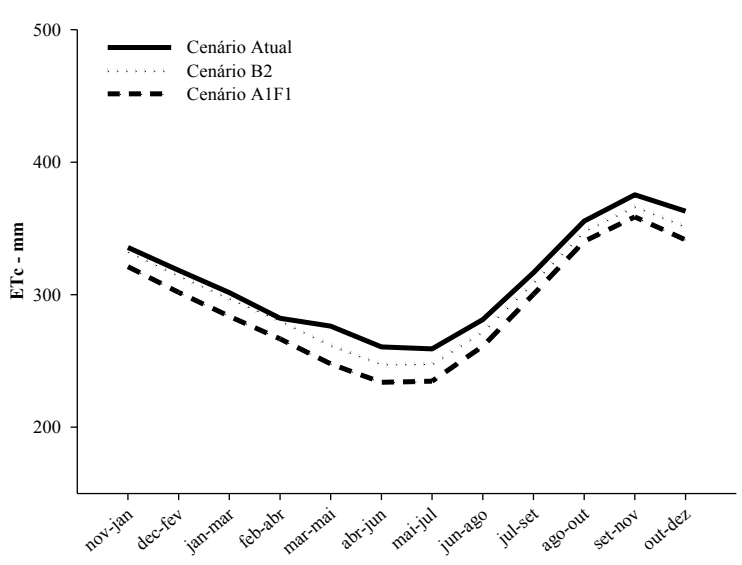

Petrolina

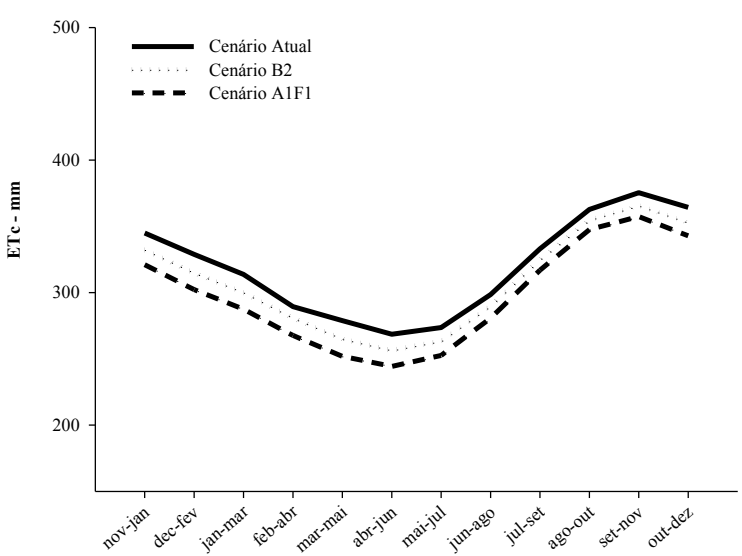

Figura 3. Demanda de água da cultura do sorgo forrageiro (evapotranspiração da cultura - ETc) cultivado nos municípios Recife, Surubim, Caruaru, Garanhuns, Pesqueira, Arcoverde, Triunfo, Floresta, Cabrobó e Petrolina no cenário Atual; Cenário $\mathrm{B} 2:+1,8^{\circ} \mathrm{C},-5,0 \%$ da $\mathrm{UR}_{\mathrm{ar}}$ e incremento de $\mathrm{CO}_{2}$ na duração do ciclo e demanda de água; Cenário $\mathrm{A} 1 \mathrm{~F} 1:+4,0^{\circ} \mathrm{C},-5,0 \%$ da $\mathrm{UR}_{\mathrm{ar}}$ e incremento de $\mathrm{CO}_{2}$ na duração do ciclo e demanda de água.

Recife

Surubim 


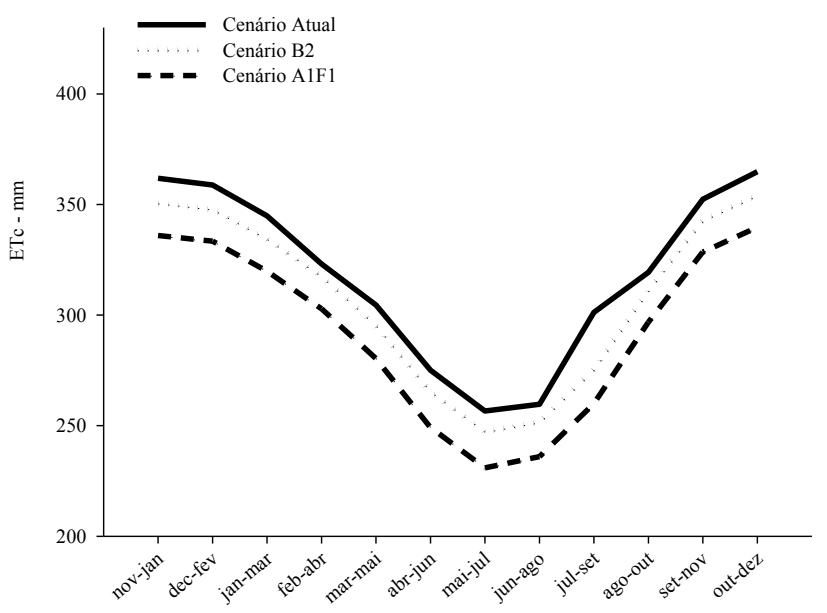

Caruaru

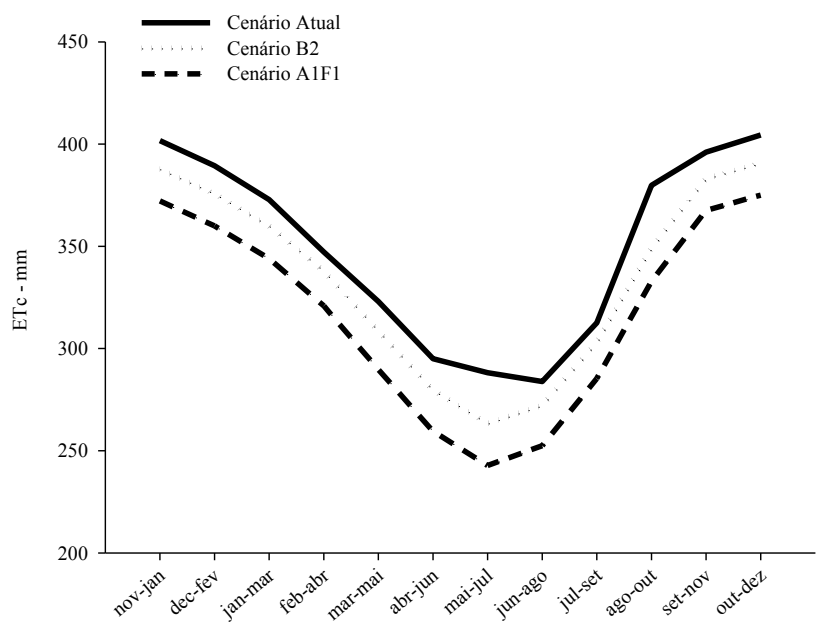

Pesqueira

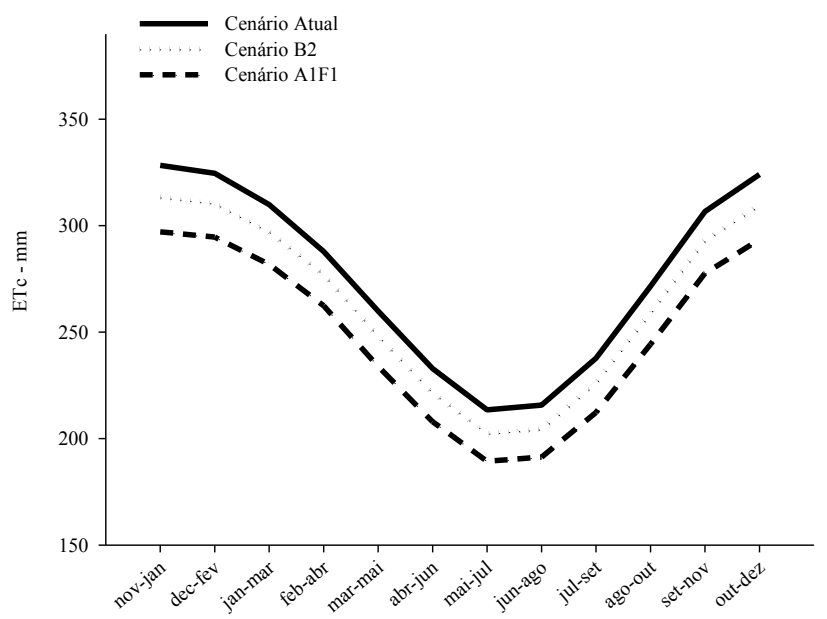

Triunfo

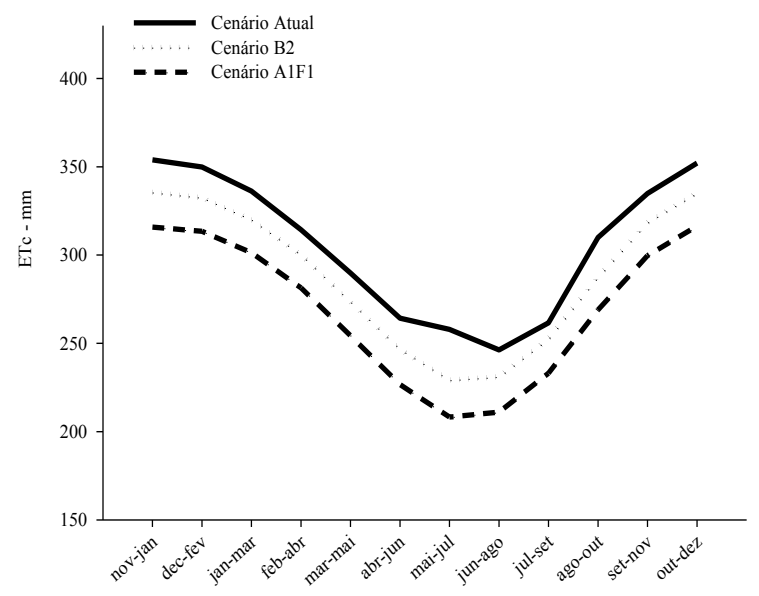

Garanhuns

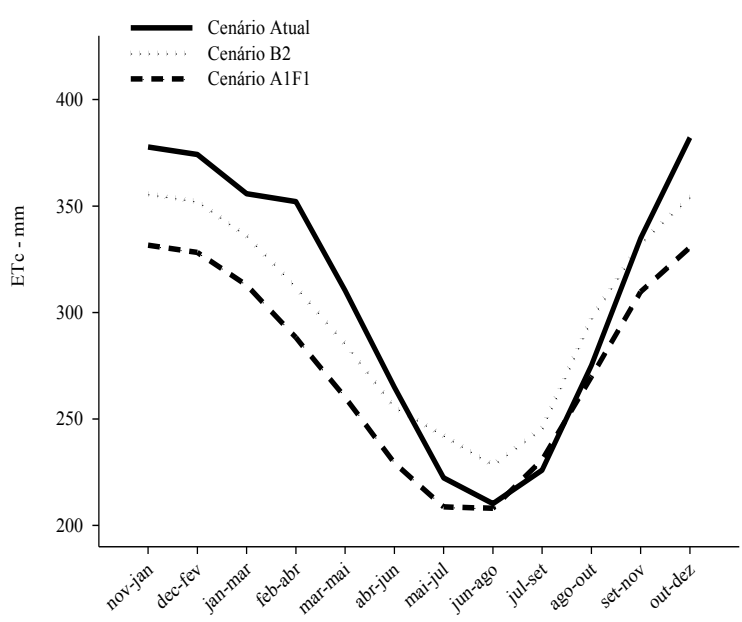

Arcoverde

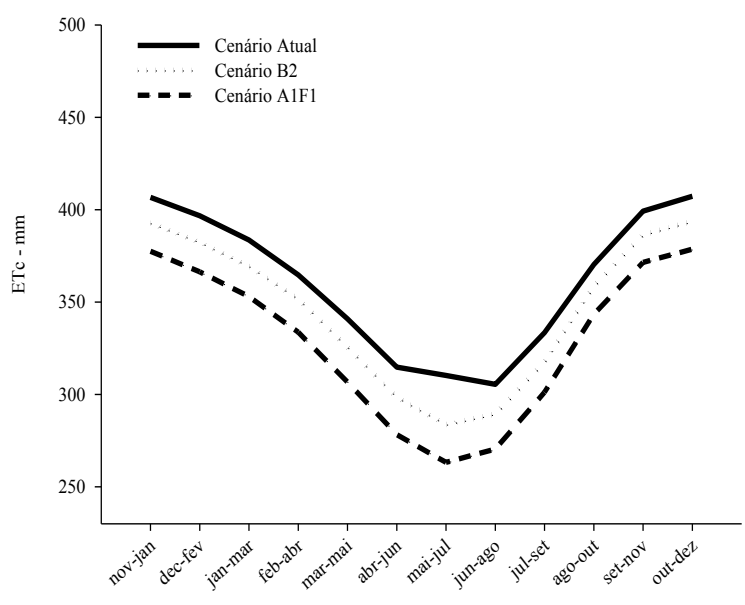

Floresta 


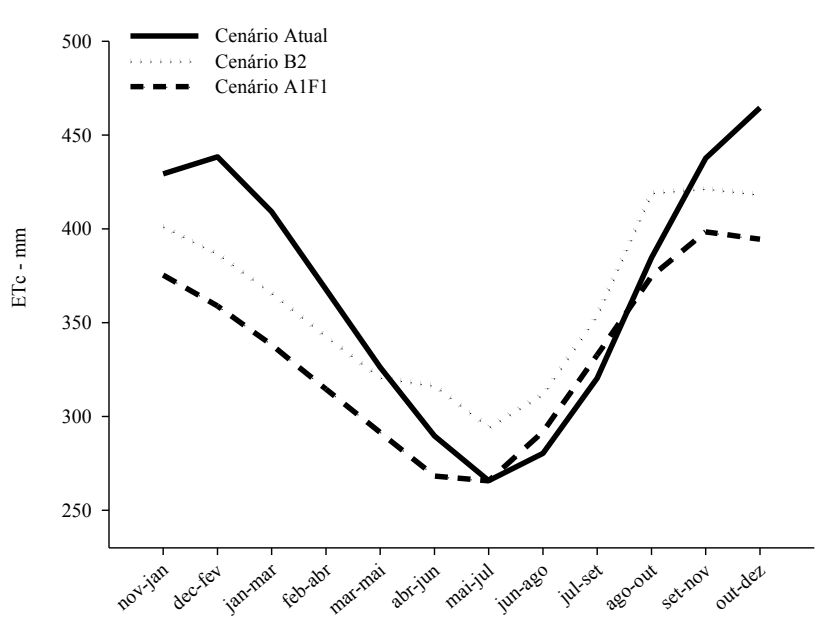

Cabrobó

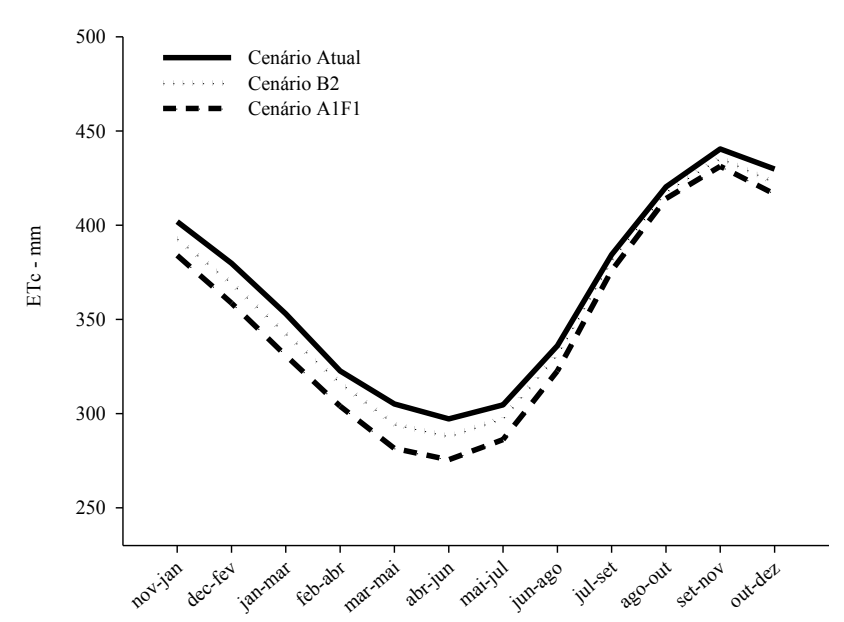

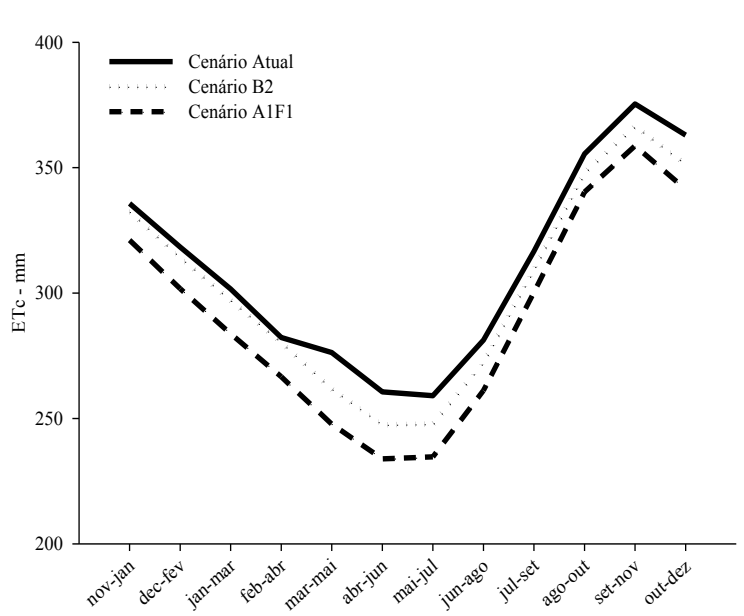

Petrolina

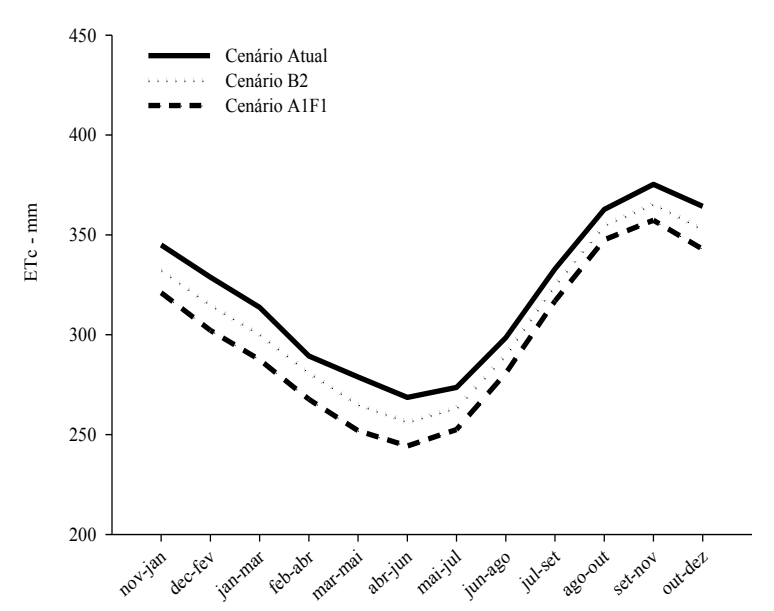

Figura 4. Demanda de água da cultura do feijão-caupi (evapotranspiração da cultura - ETc) cultivado nos municípios Recife, Surubim, Caruaru, Garanhuns, Pesqueira, Arcoverde, Triunfo, Floresta, Cabrobó e Petrolina no cenário Atual; Cenário $\mathrm{B} 2:+1,8^{\circ} \mathrm{C},-5,0 \%$ da $\mathrm{UR}_{\mathrm{ar}}$ e incremento de $\mathrm{CO}_{2}$ na duração do ciclo e demanda de água; Cenário $\mathrm{A} 1 \mathrm{~F} 1:+4,0^{\circ} \mathrm{C},-5,0 \%$ da $\mathrm{UR}_{\mathrm{ar}}$ e incremento de $\mathrm{CO}_{2}$ na duração do ciclo e demanda de água.

Segundo Lovelli et al. (2010), devido a essas peculiaridades fisiológicas e bioquímicas, as plantas $\mathrm{C} 4$ conseguem conviver em ambientes mais quentes e com elevada irradiância solar, e aumentar a taxa de fotossíntese até temperaturas de aproximadamente $36{ }^{\circ} \mathrm{C}$. Estudos realizados por Triggs et al. (2004) no Arizona (USA) com sorgo granífero revelaram que a elevação na concentração atmosférica de $\mathrm{CO}_{2}$ em $200 \mu \mathrm{mol}$ $\mathrm{mol}^{-1}$, sem alterar a temperatura ambiente reduziu a demanda de água em cerca de $13,8 \%$ da taxa da evapotranspiração relativa da cultura $\left(\mathrm{ET}_{\text {rel }}\right)$, além do aumento na eficiência do uso da água em $28 \%$. A redução da demanda de água do sorgo observada pelos autores se aproxima do valor médio para o cenário B2 (-10\%) observado no presente estudo.

Souza et al. (2008), avaliaram os efeitos do aumento do $\mathrm{CO}_{2}$ na fisiologia de plantas de canade-açúcar (C4) cultivadas em condições ambiente (370 ppm) e câmaras com ambiente controlado durante 50 semanas (720 ppm), em São Paulo, e observaram um aumento na fotossíntese $(+30 \%)$, acúmulo de biomassa $(+40 \%)$, reduções na condutância estomática e transpiração $(-37 \%$ e $32 \%$, respectivamente), e maior eficiência no uso da água $(+62 \%)$. Este estudo revelou ainda um aumento na expressão de 35 genes relacionados à fotossíntese e produtividade, mostrando a adaptação da cultura ao ambiente de cultivo enriquecido com $\mathrm{CO}_{2}$. 
Cousins et al. (2001), em estudo realizado no Arizona (USA) com plantas jovens de sorgo cultivadas em ambiente enriquecido de $\mathrm{CO}_{2}(700$ ppm) e sob estresse hídrico, observaram um aumento na taxa fotossintética. Algumas razões podem explicar o efeito positivo do aumento de $\mathrm{CO}_{2}$ associado ao estresse na resposta das plantas $\mathrm{C} 4$, principalmente, saturação enzima Ribulose 1,5-bisfosfato carboxilase/oxigenase (Rubisco) com $\mathrm{CO}_{2}$ e a redução na abertura estomática sob estresse que aumenta eficiência do uso de água com a redução da transpiração, além de elevar a temperatura da folha fornecendo a temperatura ótima para a fotossíntese (Ainsworth e Rogers, 2007).

Essas respostas podem variar em relação às espécies C3. Magliulo et al. (2003), constataram para a cultura do tomateiro e trigo (C3) que o enriquecimento de $\mathrm{CO}_{2}$ reduziu em $11,8 \%$ e $7 \%$, respectivamente, o uso de água total sob condições de disponibilidade de água no solo quando comparado ao controle $\left(360 \mu \mathrm{mol} \mathrm{m}^{-2} \mathrm{~s}^{-1}\right)$. Porém, essas reduções não tem sido padrão para todas as culturas C3. Hunsaker et al. (1994) não observaram influências significativas sobre a $\mathrm{ET}_{\text {rel }}$ para a cultura doa algodoeiro (C3) devido ao aumento da concentração de $\mathrm{CO}_{2}$ do ambiente (+ $\left.180 \mu \mathrm{mol} \mathrm{m}^{-2} \mathrm{~s}^{-1}\right)$.

\section{Conclusões}

A magnitude das reduções da duração do ciclo e a demanda de água simulada para as culturas do sorgo forrageiro e do feijão-caupi variaram espaço-temporalmente no estado de Pernambuco em decorrência dos efeitos combinados do aumento da temperatura do ar, redução da umidade relativa do ar e do incremento de $\mathrm{CO}_{2}$ na atmosfera para os cenários de mudanças climáticas. Esses resultados contrariam estudos que informam o aumento da demanda de irrigação de culturas agrícolas devido às mudanças climáticas, uma vez que assumem apenas o efeito da temperatura do ar, desprezando a influência do incremento de $\mathrm{CO}_{2}$ sobre os processos metabólicos das plantas.

\section{Referências}

AGRIANUAL. Anuário da Agricultura Brasileira, 2010. Feijão: ofertas e demandas brasileiras. São Paulo.

Ainsworth, E.A., Long, S.P., 2005. What have we learned from 15 years of free-air $\mathrm{CO}_{2}$ enrichment (FACE)? A meta-analytic review of the responses of photosynthesis, canopy properties and plant production torising $\mathrm{CO}_{2}$.

New Phytologist 165, 351-372.

Ainsworth, E.A., Rogers, A., 2007. The response of photosynthesis and stomatal conductance to rising $\left[\mathrm{CO}_{2}\right]$ : mechanisms and environmental interactions. Plant, Cell \& Environment 30, 258270.

Allen, R.G., Pereira, L.S., Raes, D., Smith, M., 1998. Crop evapotranspiration: guidelines for computing crop water requirements. FAO, Rome. (FAO. Irrigation and Drainage Paper, 56).

Alvares, C.A., Stape, J.L., Sentelhas, P.C., Gonçalves, J.L.M., Sparovk, G., 2014. Köppen's climate classification map for Brazil. Meteorologische Zeitschrift22, 711-728.

Assis, F.N., Verona, L.A.F., 1991. Consumo de água e coeficiente de cultura do sorgo. Pesquisa Agropecuária Brasileira 26, 665-670.

Beltrão, N.E.M., 2008. Diálogos da terra e os efeitos do aquecimento global na agricultura do semi-árido nordestino. Embrapa Algodão, Campina Grande. Disponível: http://www.cnpa.embrapa.br/ noticias/ 2008/noticia_20081127.html. Acesso: 27 ago. 2013.

Bernacchi, C.J., Kimball, B.A., Quarles, D.R., Long, S.P., Ort, D.R., 2007. Decreases in stomatal conductance of soybean under openair elevation of $\left[\mathrm{CO}_{2}\right]$ are closely coupled with decreases in ecosystem evapotranspiration. Plant Physiology 143, 134-144.

Brasil, 2009. Zoneamento de risco climático para a cultura do sorgo em Pernambuco. Disponível: $\mathrm{http}: / /$ www.agricultura.gov.br/pls/portal/docs/p agp/mapa/legislacao/publicacoes_dou/publicac oes_d_2009/ dou_novembro 2009/do1_16_11_0_0_0.pdp. Acesso: 10 jun. 2013.

Brutsaert, W.H., Stricker, H., 1979. An advection aridity approach to estimate actual regional evapotranspiration. Water Resour15, 443-450.

CONAB. Companhia Nacional de Abastecimento, 2013. Central de informações agropecuárias. Disponível: http://www.conab.gov.br/ conab web/ index. ph p? $\mathrm{PAG}=101$. Acesso: 23 jun. 2013.

Cousins, A.B., Adam, N.R., Wall, G.W., 2001. Reduced photorespiration and increased energy-use efficiency in young $\mathrm{CO}_{2}$-enriched sorghum leaves. New Phytologist 150, 275284.

FAO. Food and Agriculture Organization of the United Nations, 2007. Faostat Agriculture. Disponível:

http: // apps. fao. org. Acesso: 08 maio 2013. 
Freire Filho, F.R., 2011. Feijão-caupi no Brasil: produção, melhoramento genético, avanços e desafios. Embrapa Meio Norte, Teresina, 84 p.

Furtado, G.F., Souza, A.S., Sousa Júnior, J.R., Sousa, J.R.M; Lacerda, R.R.A., Silva, S.S., 2014. Rendimento e correlações da mamoneira consorciada com feijão-caupi e gergelim no semiárido paraibano. Revista Brasileira de Engenharia Agrícola e Ambiental 18, 892-898.

Ghannoum O., Von Caemmerer, S., Ziska L.H., 2000. The growth response of $\mathrm{C} 4$ plants to rising atmospheric $\mathrm{CO} 2$ partial pressure: a reassessment. Plant, Cell \& Environment 23, 931-942.

Gondim, R.S., Castro, M.A.H., Teixeira, A.S., Evangelista, S.R.M., 2011. Impactos das mudanças climáticas na demanda de irrigação da bananeira na Bacia do Jaguaribe. Revista Brasileira de Engenharia Agrícola e Ambiental 15, 594-600.

Godoy, J.F.L., 2007. Ecofisiologia do estabelecimento de leguminosas arbóreas da Mata Atlântica, pertencentes a diferentes grupos funcionais, sob atmosfera enriquecida com $\mathrm{CO}_{2}$ : uma abordagem sucessional. Tese (Doutorado). São Paulo, Instituto de Botânica de São Paulo.

Grandis, A., Godoi, S., Buckeridge, M.S., 2010. Respostas fisiológicas de plantas amazônicas de regiões alagadas às mudanças climáticas globais. Revista Brasileira de Botânica 33, 1-12.

Hunsaker, D.J., Hendrey, G.R., Kimball, B.A., Lewin, K.F., Mauney, J.R., Nagy, J., 1994. Cotton evapotranspiration under field conditions with $\mathrm{CO}_{2}$ enrichment and variable soil moisture regimes. Agricultural Forest Meteorology 70, 247-258.

IPCC. Intergovernmental Panel on Climate Change, 2007. Climate change 2007: The Physical Science Basis. Contribution of working groups I, II and III to the Fourth Assessment Report of the Intergovernmental Panel on Climate Change. OMM/PNUMA, Geneva. 114p. Disponível:

http://www.ipcc.ch/pdf/assessmentreport/ar4/syr /ar4_syr_sp.pdf. Acesso: 05 fev. 2011.

IPCC. Intergovernmental Panel on Climate Change, 2013. Climate change 2013: The Physical Science Basis. Contribution of working group I to the Fifth Assessment Report of the Intergovernmental Panel on Climate Change. Cambridge University Press, Cambridge, United Kingdom and New York, NY, USA. 1552p. Disponível: http://www. Climatechange 2013. org/ images/ report/ WG1AR 5_ALL_ FINAL. pdf. Acesso: 05 fev. 2015.
INMET. Instituto Nacional de Meteorologia, 2014. Normais climatológicas do Brasil 1961 - 1990. Disponível: http://www.inmet.gov.br/ portal/ index. php? $\mathrm{r}=\mathrm{clima} /$ normais Climatologicas. Acesso: 15 fev. 2014.

Lacerda, F.F., 2010. Aquecimento global: conceituação e repercussões sobre o Brasil. Revista Brasileira de Geografia Física 3, 14-17.

Lima, R.C.C., Cavalcante, A.M.B., Perez-Marin, A.M., 2011. Desertificação e mudanças climáticas no semiárido brasileiro. INSA-PB, Campina Grande. Disponível: http://www.insa.gov.br/ wp - contente/ themes/insa_theme/acervo/desertificacao-eudancas - climaticas. pdf. Acesso: 12 fev. 2015.

Lloyd, J., Fanquhar, G.D., 2008. Effects of rising temperatures and $\left[\mathrm{CO}_{2}\right]$ on the physiology of tropical forest trees. Philosophical Transactions of the Royal Society B 63, 1811-1817. doi: 10.1098/rstb.2007.0032.

Lovelli, S., Perniola, M., Tommasoa, T.D.I., Ventrella, D., Moriondo, M., Amato, M., 2010. Effects of rising atmospheric $\mathrm{CO}_{2}$ on crop evapotranspiration in a Mediterranean area. Agricultural Water Management 97, 1287-1292.

Magliulo, V., Bindi, M., Rana, G., 2003. Water use of irrigated potato (Solanumtuberosum L.) grown under free air carbon dioxide enrichment in central Italy. Agriculture, Ecosystems and Environmental 97, 65-80.

Marabesi, M.A., 2007. Efeito do alto $\mathrm{CO}_{2}$ no crescimento inicial e na fisiologia da fotossíntese em plântulas Senna alata (L.) Roxb.. Tese (Doutorado). São Paulo-SP, Instituto de Botânica de São Paulo.

Miranda, M.N., Campelo Júnior, J.H., 2010. Soma térmica para o subperíodo semeaduramaturação de feijão cv. Carioca em Colorado do Oeste, Rondônia. Pesquisa Agropecuária Tropical 40, 180-185.

Monteith, J.L., 1965. Evaporation and environment, in: Fogg, G.E. (Ed.), The State and Movement of Water in Living Organism. Society for Experimental Biology. v.19. Academic Press, New York, pp. 205-234.

Nobre, P., 2011. Desertificação e mudanças climáticas no semiárido brasileiro. INSA-PB, Campina Grande.

Oyama, M.D., Nobre, C.A., 2003. A new climatevegetation equilibrium state for Tropical South America. Geophysical Research Letter 30, 2199-2203. doi: 10.1029/2003GL018600.

Raven, P.H., Evert, R.F., Eichhorn, S.E., 2014. Biologia Vegetal. 8 ed. Guanabara Koogan S.A., Rio de Janeiro. 
Reboita, M.S., Rocha, R.P., Dias, C.G., Ynoue, R.Y., 2014. Climate Projections for South America: RegCM3 Driven by HadCM3 and ECHAM5. Advances in Meteorology 2014, 117. doi: 376738.

Rocha, M.M., Carvalho, K.J.M., Freire Filho, F.R., Lopes, A.C.A., Gomes, R.L.F., Sousa, I.S., 2009. Controle genético do comprimento do pedúnculo em feijão-caupi. Pesquisa Agropecuária Brasileira 44, 270-275.

Rocha, R.P., Cuadra, S.V., Reboita, M.S., Kruger, L.F., Ambrizzi, T., Krusche, N., 2012. Effects of RegCM3 parameterizations on simulated rainy season over South America, Climate Research 52, 253-265. doi: 10.3354/cr01065.

Rodrigues Filho, O., França, A.F.S., Oliveira, R.P., Oliveira, E.R., Rosa, B., Soares, T.V., Mello, S.Q.S., 2006. Produção e composição de quatro híbridos de sorgo forrageiro (Sorghum bicolor L. Moench) submetidos a três doses de nitrogênio. Ciência Animal Brasileira 7, 37-48.

Silva, E.F., Barros Júnior, A.P., Silveira, L.M., Santana, F.M.S., Santos, M.G., 2013. Avaliação de cultivares de feijão-caupi irrigado para produção de grãos verdes em Serra Talhada-PE. Revista Caatinga 26, 21-26.

Solomon, S., Qin, D., Manning, M., Chen, Z., Marquis, M., Averyt, K.B., Tignor, M., Miller, H.L., 2007. Contribution of Working Group I to the Fourth Assessment Report of the Intergovernmental Panel on Climate Change. Cambridge University Press, Cambridge, United Kingdom and New York.

Souza, A.P., Gaspar, M., Silva, E.A., Ulian, E.C., Waclawovsky, A.J., Nishiyama Junior, M.Y.,
2008. Elevated $\mathrm{CO}_{2}$ increases photosynthesis, biomass and productivity, and modifies gene expression in sugarcane. Plant, Cell and Environment 31, 1116- 1127.

Tabosa, J.N., Tavares, J.A., Reis, O.V., Simplício, J.B., Lima, J.M.P., Carvalho, H.W.L., Nascimento, M.M.A., 2007. Potencial do Sorgo Granífero em Pernambuco e no Rio Grande do Norte: resultados obtidos com e sem irrigação. Revista Brasileira de Milho e Sorgo 5, 339-350.

Taiz, L., Zeiger, E., 2009. Fisiologia vegetal. 4 ed. Artmed Editora S.A., Porto Alegre.

Triggs, J.M., Kimball, B.B.A., Pinter Jr, P.J., 2004. Free-air $\mathrm{CO}_{2}$ enrichment effects on the energy balance and evapotranspiration of sorghum. Agricultural and Forest Meteorology 124, 63-79.

Urban, L., Six, S., Barthélémy, L., Bearez, P., 2002. Effect of elevated $\mathrm{CO} 2$ on leaf water relations, water balance and senescence of cut roses. Journal Plant Physiology 159, 717-723.

Valverde, M.C., Marengo, J.A., 2014. Extreme rainfall índices in the hidrographic basins of Brazil. Open Journal of Modern Hidrology 4, 10-26. doi: 10.4236/ojmh.2014.41002.

Wall, G.W., Brooks, T.J., Adam, N.R., Cousins, A.B., Kimball, B.A., Pinter Jr, P.J., La Morte, R.L., Triggs, J., Ottman, M.J., Leavitt, S.W., Matthias, A. D., Williams, D.G., Webber, A.N., 2001. Elevated atmospheric CO2 improved Sorghum plant water status by ameliorating the adverse effects of draught. New Phytologist 152, 231-248. 